University of Rhode Island

DigitalCommons@URI

Open Access Dissertations

1999

\title{
Antihypertensive Pharmacotherapy: Does Prescribing Follow National Guideline Recommendations?
}

Edward Roy Westrick

University of Rhode Island

Follow this and additional works at: https://digitalcommons.uri.edu/oa_diss

\section{Recommended Citation}

Westrick, Edward Roy, "Antihypertensive Pharmacotherapy: Does Prescribing Follow National Guideline Recommendations?" (1999). Open Access Dissertations. Paper 191.

https://digitalcommons.uri.edu/oa_diss/191

This Dissertation is brought to you for free and open access by DigitalCommons@URI. It has been accepted for inclusion in Open Access Dissertations by an authorized administrator of DigitalCommons@URI. For more information, please contact digitalcommons-group@uri.edu. 
ANTIHYPERTENSIVE PHARMACOTHERAPY: DOES PRESCRIBING FOLLOW NATIONAL GUIDELINE RECOMMENDATIONS?

BY

EDWARD ROY WESTRICK

A DISSERTATION SUBMITTED IN PARTIAL FULFILLMENT OF THE REQUIREMENTS FOR THE DEGREE OF DOCTOR OF PHILOSOPHY

IN

PHARMACEUTICAL SCIENCES

UNIVERSITY OF RHODE ISLAND 1999 
DOCTOR OF PHILOSOPHY DISSERTATION

OF

EDWARD ROY WESTRICK

APPROVED:

Dissertation Committee

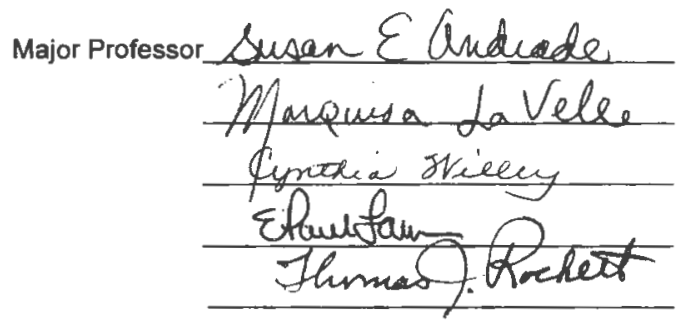

DEAN OF THE GRADUATE SCHOOL

UNIVERSITY OF RHODE ISLAND

1999 


\begin{abstract}
Background

Hypertension is a common chronic disease, which is expensive to treat and has serious but preventable long-term complications. It should be possible to optimize antihypertensive therapy such that the most prevention is obtained with the least cost. This optimization can be approached through adherence to current national evidence-based practice guidelines for the treatment of hypertension.

Objectives
\end{abstract}

The objectives of this study are: (1) to test hypotheses regarding comorbidities and prescribing in hypertension and, (2) to identify opportunities to improve adherence to treatment guidelines for hypertension. Methods

The study employs a nonconcurrent cohort research design for hypothesis testing in incident uncomplicated cases of hypertension. The practice recommendations from the Joint National Committee on Prevention, Detection, Evaluation, and Treatment of High Blood Pressure were translated into operational definitions of uncomplicated hypertension, relevant comorbidities, and drug class prescribing. Administrative claims data were used to classify cases with respect to diseases and classes. These classifications were used to test for predicted disease-class associations. 
Results

Multivariate adjusted odds ratios (OR) and $95 \%$ confidence intervals (CI) for significant associations include: Angiotensin Converting Enzyme (ACE) inhibitor (5.88 OR, 2.57-13.43 Cl) and diuretic (10.87 OR, 4.70-25.15 C1) prescribing positively associated with congestive heart failure; betablocker (4.39 OR, 2.93-6.56 95\% Cl) and calcium channel blocker (CCB) (2.70 OR, 1.88-3.86) prescribing positively associated with coronary artery disease; beta-blocker prescribing negatively associated with chronic obstructive pulmonary disease $(0.50 \mathrm{OR}, 0.33-0.75 \mathrm{Cl})$ and diabetes mellitus $(0.56 \mathrm{OR}$, $0.38-0.82 \mathrm{CI}$ ); and $\mathrm{ACE}$ inhibitor prescribing positively associated with diabetes mellitus (1.73 OR, 1.38-2.16 Cl). Additional significant associations were found in bivariate analyses reported as unadjusted relative risks (RR) and $95 \%$ confidence intervals (CI) including: a positive association of ACE inhibitor prescribing in renal failure $(1.84 \mathrm{RR}, 1.11-3.04 \mathrm{Cl})$ and negative associations between diuretic (0.69 RR, 0.58-0.83 Cl) and beta-blocker $(0.62$ RR, 0.50-0.77 Cl) prescribing with dyslipidemia. Diuretics and beta-blockers $(38.8 \%)$ are not used more frequently as first line therapy than CCBs and ACE inhibitors $(59.7 \%)$ in uncomplicated hypertension.

Conclusions

The predicted associations were largely confirmed, providing evidence for appropriate prescribing in hypertension. Analysis of claims data can be a useful method of measuring prescribing practices in hypertension. The details of this methodology and its limitations are discussed. The major opportunity 
for improvement relates to under-prescribing of diuretics and beta-blockers, and over-prescribing of calcium channel blockers and ACE inhibitors in uncomplicated hypertension. 


\section{ACKNOWLEDGMENTS}

I want to thank the Hawaii Medical Services Association (HMSA) Foundation for providing the data on which this study was conducted. The HMSA Foundation is a private grantmaking charity affiliated with the HMSA. Its primary activities include grantmaking, research, education and community service publications.

I want to thank my dissertation committee for ongoing advice on analyses and revisions, and for their patience over the last couple of years. I want to thank my family for their patience while I took more than 17 years to finally finish graduate school.

Lastly, I'd like to dedicate this work to Albert Taubman with whom I originally started this investigation. He was a respected mentor to many students. I thank him not only for his collaboration on this project but for helping me to find my true career direction. I shall always grateful to Al for the fun that I have doing the meaningful work that he helped me to find as my calling. 


\section{PREFACE}

This dissertation was prepared in the format of the standard dissertation plan. There is one manuscript divided into six sections. These include the statement of the problem, introduction, methods, results, discussion, and bibliography. Two appendices follow the manuscript. Tables appear at the end of the body of the text. 
TABLE OF CONTENTS

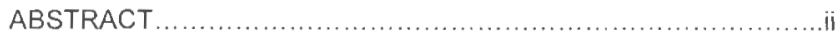

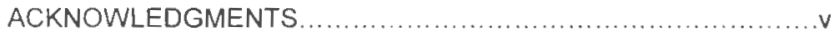

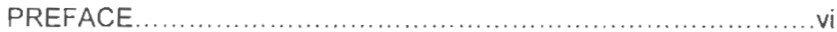

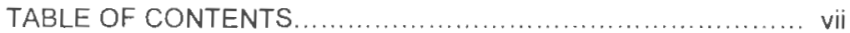

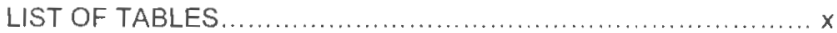

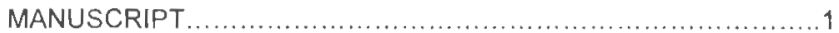

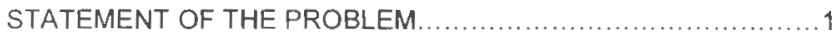

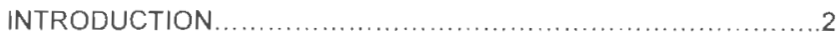

Health Care Quality Improvement...........................2

Quality Measurement ........................................ 4

Guidelines................................................. 6

Epidemiology of Hypertension ..................................

Impact of Hypertension ........................................ 7

Treatment of Hypertension.................................. 9

Selection of Antihypertensive Agents........................ 12

Measurement Methodology .................................. 14

Hypotheses.............................................. 17 
TABLE OF CONTENTS

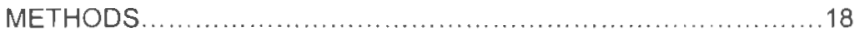

Research Design............................................. 18

Patient Population............................................. 18

Database ....................................................... 19

Data Cleaning ................................................ 20

Disease Definitions .............................................

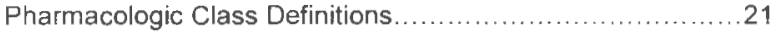

Univariate Analyses ........................................22

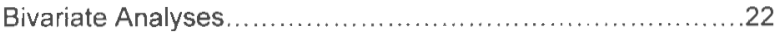

Multivariate Analyses..........................................22

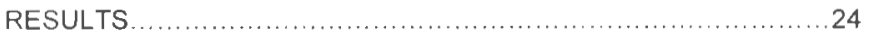

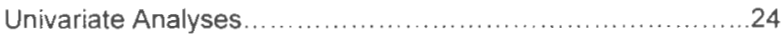

Bivariate Analyses............................................. 27

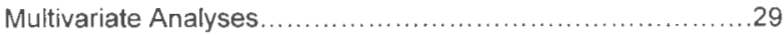


TABLE OF CONTENTS

DISCUSSION ..................................................... 31

Limitations................................................. 33

Measurement issues..................................... 36

Practical Applications..........................................37

Opportunities For Improvement............................37

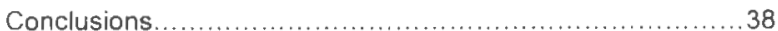

APPENDIX A: Alternatives for Operational Definitions

of Prevalent Cases.............................................. 51

APPENDIX B: Abbreviations of Comorbidity Clusters

and Drug Classes............................................. 56

BIBLIOGRAPHY ................................................. 57 


\section{LIST OF TABLES}

Tabie 1. ICD-9 CM Code Sets for Operational Definitions of Prevalent Cases of Hypertension and

Relevant Comorbidities.

Table 2. Frequencies and Proportions of Demographics \&

Relevant Comorbidities in Prevalent Hypertension and

Incident, Uncomplicated Hypertension.

Table 3. Frequencies and Proportions of Patients Dispensed

Drug Classes in Prevalent Hypertension and in Incident,

Uncomplicated Hypertension.

Table 4. Drug Classes Dispensed in Incident, Uncomplicated

Cases of Hypertension with No Relevant Comorbidities...

Table 5. Order of Therapeutic Class in Treatment Regimens

in Incident Uncomplicated Cases of Hypertension.

Table 6. Unadjusted Risk Ratios and Confidence Intervais for Selected Bivariate Relationships in Incident, Uncomplicated

Cases of Hypertension

Tabie 7. Adjusted Odds Ratios and Confidence Intervals from Logistic Regression Analyses in Incident, Uncomplicated

Cases of Hypertension 


\section{MANUSCRIPT}

\section{STATEMENT OF THE PROBLEM}

The purposes of the study are to measure the infiuence of comorbid medical conditions on the prescribing of antihypertensive drug therapeutic classes and to identify opportunities for improvement in prescribing. It is expected that known indications and contraindications influence the selection of pharmaceutical classes for the treatment of hypertension. The magnitude of this effect has not been estimated. A large administrative medical claims database will provide a useful window into current prescribing practices. This study will serve to identify opportunities for improvement in pharmacotherapeutic aspects of hypertension management. The results will be useful in efforts to improve selection of antihypertensive agents. 


\section{INTRODUCTION}

Hypertension is a common chronic disease in adults with harmful consequences that can be prevented with effective therapy. Hypertension is treated by lifestyle modification and when necessary, pharmacologic therapy. The goal of therapy is to reduce blood pressure without intolerably impairing patients' quality of life. Individualization of therapy is important in reaching optimal outcomes. Comorbid conditions, demographic variables, economic considerations, side effect profiles, and patient preferences should influence the individualization of therapy. There can be however, unexplained and even undesirable influences on practice variation (Kaplan, 1994; Kaplan, 1998a) The details of therapy are important to study because of their associated costs and outcomes. It can be estimated that the wholesale costs for the top four classes of antihypertensive agents exceeded $\$ 5$ billion in 1995 (Siegel and Lopez, 1997). Heart disease and stroke are the first and third leading causes of death in this country and are both associated with hypertension. The financial burden alone for these illnesses has been estimated at over $\$ 259$ billion in direct and indirect costs (JNC 6, 1997). For these reasons, hypertension is a useful condition to study for the purposes of health care quality improvement.

Health Care Quality Improvement

The health care delivery system in the United States is going through rapid evolutionary change (Drake, 1997). The stimuli for these changes are largely economic; however, issues of quality have started taking center stage 
(President's Advisory Commission on Consumer Protection and Quality in the Health Care Industry, 1998). The concepts of Quality and Cost can be combined, studied, and understood using the Health Care Value Equation (Toscani, 1997):

$$
\text { Value }=\text { Quality } / \text { Cost }
$$

It is useful to think about maximizing Value as the goal of our health care delivery system. This can be accomplished by increasing Quality while holding Cost constant or decreasing Cost while holding Quality constant. Critics of managed care might argue that some managed care organizations (MCO) are increasing Value by cutting Costs at the expense of smaller reductions in Quality.

The modern practice of Health Care Quality Improvement (Jencks and Wilensky, 1992) approaches the equation in a different way. Ideally, the goal of health care quality improvement is to maximize Value by both increasing Quality and decreasing Cost. This can be accomplished only through systematic approaches to performance improvement. These systematic approaches require frequent measurement for the purposes of identifying opportunities for improvement, root cause analysis, design of interventions, and evaluation of the interventions (Melum, 1995). Reliable, objective, low cost measurement is essential to this method of performance improvement. The models developed in this doctoral dissertation should be useful for systematic efforts to measure and improve performance in the treatment of hypertension. Such improved performance should increase Value as it relates 
to the treatment of hyperterision.

Hypertension has two sets of costs, those associated with treatment and those associated with consequences of the disease. From a health economic perspective, optimal Value occurs when we maximize the prevention of long-term complications of hypertension while we minimize the costs associated with treatment. Costs are relatively easy to quantify; quality is more difficult.

\section{Quality Measurement}

Quality has been defined as "the degree to which health services for individuals and populations increase the likelihood of desired health outcomes and are consistent with current professional knowledge" by the Institute of Medicine (Palmer, 1997). Donabedian proposed a framework for measuring quality more than 30 years ago that still influences current thinking on these issues (Donabedian, 1966). He suggested that data for quality measurement should be classified according to the structures, processes, and outcomes of care. The outcomes are the results or consequences of disease and health services. These outcomes can include changes in health status (morbidity and mortality) or more subjective measures (quality of life or functional status). The processes are the health services and other actions used to produce outcomes. The structures are the people, places, and things used to deliver those services and other actions. Modern quality science has largely moved away from the earlier structural measures to those of outcomes and processes. For performance improvement purposes, outcomes often take too 
long to occur and can be due to influences other than the processes under the system's control and statistical methods cannot always adjust for these confounding influences. Therefore, process measurement has become the more common method in quality improvement science. Systematic performance improvement approaches focus primarily on processes and the IOM definition of quality is primarily process oriented. At the level of processes, quality can been more simply defined as doing the right things, and doing them well (JCAHO, 1994).

The right things "increase the likelihood of desired health outcomes and are consistent with current professional knowledge." These principles call for evidence of known process-outcome relationships with strong evidence bases supporting them. In the absence of best evidence, expert consensus opinion can suffice. These "right things" are currently defined by practice guidelines with varying degrees of evidence supporting their recommendations. These principles are also consistent with the growing movement called "Evidence Base Medicine." One of the leaders of this movement describes: "Evidence based medicine is the conscientious, explicit, and judicious use of current best evidence in making decisions about the care of individual patients. The practice of evidence based medicine means integrating individual clinical expertise with the best available external clinical evidence from systematic research ..." (Kaplan, 1998a).

Peer reviewed literature can supplement the recommendations of practice guidelines. Health care quality improvement science uses the 
recommendations of practice guidelines, develops measurable indicators of performance, and uses the results of such measurement to identify opportunities for improvement. Objective measurement can be used to develop interventions to improve performance on a system-wide basis. Repeat measurements are used to evaluate the effects of targeted interventions. To suit these purposes, measurement should be relatively inexpensive and unobtrusive. The measures developed in this study should meet those requirements. These measurements should be relatively inexpensive because they will be derived from data already collected. Expensive chart abstraction can be avoided. These measures should be unobtrusive because the data collection occurs retrospectively and there is no burden on the practitioners.

\section{Guidelines}

There are well accepted, evidence based guidelines for the treatment of hypertension that are revised by a national panel of experts every four to five years. This expert panel, the Joint National Committee on Prevention, Detection, Evaluation, and Treatment of High Blood Pressure (JNC 5, 1994; JNC 6, 1997) was brought together as part of the National High Blood Pressure Education Program (NHBPEP) by the National Heart, Lung, and Blood Institute (NHLBI) of the National Institutes of Health $(\mathrm{N} \mid \mathrm{H})$. The continuing effort has lasted more than a quarter century. The reports of the $5^{\text {th }}$ and $6^{\text {th }}$ committees are used in this study. The recommendations of the $5^{\text {th }}$ report were used to create the quality indicators and the study interval (1994- 
1996) fell within the period after the $5^{\text {th }}$ and before the $6^{\text {th }}$ reports. The results are discussed with respect to the recommendations of both the $5^{\text {th }}$ and $6^{\text {th }}$ reports.

\section{Epidemiology of Hypertension}

Hypertension is the most prevalent disease in this country, affecting approximately 50 million adults ( $28 \%$ of the adult population) when estimated in 1988-1991 (Burt, Whelton, Roccella et al, 1995). Blood pressure increases with age; the prevalence exceeds $50 \%$ at ages greater than or equal to 60 (Margolis and Klag, 1998). Most people will develop hypertension at some time during their lives. Hypertension is the second most common reason for visits to physicians in this country, more than 100 million annually (Kaplan, 1998c). Other risk factors for hypertension include race, obesity, diabetes mellitus, and family history of hypertension (Burt et al, 1995; Margolis and Klag, 1998).

\section{Impact of Hypertension}

Consequences of hypertension are important in terms of morbidity, mortality, and health service costs. Sustained hypertension is associated with higher overall mortality rate, stroke, myocardial infarction, and kidney disease (Kaplan, 1998d). Morbidities associated with hypertension are expressed as end organ damage of the heart, brain, kidneys, eyes, and biood vessels.

Heart disease associated with hypertension takes two forms, coronary artery disease and congestive heart failure. Hypertension contributes toward the progression of atherosclerotic disease and increases the workload on the 
left ventricle. Atherosclerosis in the coronary arteries causes a decrease in blood flow to the heart and can result in tissue ischemia, experienced as symptomatic disease (angina), or tissue death (myocardial infarction). The increase in workload on the left ventricle causes the heart muscle to hypertrophy and eventually to fail (Levy, Larson, Ramachandran et al, 1996). The heart is considered to be in failure when it can no longer pump an adequate supply of blood to the vital organs.

The brain is effected by hypertension primarily by two pathophysiologic processes, atherosclerotic disease and aneurysmal dilatation (Margolis and Klag, 1998; Kaplan (1998d). Hypertension contributes toward atherosclerotic disease of the cerebrovascular system that can result in inadequate blood supply to the brain. If the deficiency causes symptoms that are temporary, the syndrome is called a transient ischemic attack (TIA). If the deficiency results in brain tissue death, it is called a stroke. Hypertension can cause rupture of a cerebral aneurysm resulting in an intracerebral hemorrhage.

The kidneys are damaged by atherosclerotic disease of the large arteries to the kidneys and by disease of the smaller arteries of the kidneys. Kidney disease can lead to long term dialysis or kidney transplantation. Kidney disease also contributes toward high blood pressure. Vision can be impaired when hypertension causes damage to the small vessels of the eyes (Kaplan, 1998d).

Vascular disease secondary to hypertension can take other forms. Peripheral vascular disease (PVD) typically involves atherosclerosis of the 
large vessels in the legs. The reduced blood supply can cause symptoms of claudication (ischemic leg pain) and can cause tissue death. Treatment of PVD often involves bypass surgery. Severe disease can lead to amputation. Hypertension can cause weakening in vessel walls that can lead to rupture of the vessel. The rupture of a large artery (e.g. aorta) results in a catastrophic bleed (Kaplan, 1998d).

These consequences have costs in terms of human suffering and lost productivity; however, these costs are difficult to measure. The costs of the health services associated with these consequences are easier to measure. These include professional services, hospitalization services, and medications. Professional services include physicians and other health care provider interventions. Hospitalization services include medical, surgical, and rehabilitation interventions. Medications include the drugs used to treat the consequences of hypertension. Precise measurement of these costs would be important in assessing the overall Value in the treatment of hypertension. Since this study focuses on quality, such precise cost estimates are beyond the scope of this investigation. Just to place some of these costs in perspective, hypertension is the second most common indication for physician office visits and cardiovascular drugs are the most commonly prescribed category of pharmaceutical agents (Woodwell, 1997).

\section{Treatment of Hypertension}

Hypertension can be successfully treated. Effective treatment lowers risk for end organ damage and mortality (Kannel, 1996) (14). The treatment of 
hypertension includes lifestyle modification (Kaplan, 1998e) or nonpharmacologic therapy and the use of drugs when necessary (Kaplan, 1998a). The goal of treatment is to lower blood pressure without intolerably impairing the quality of life.

Lifestyle modification includes weight loss for people who are obese, dietary change that can include a reduction in salt (TOMHS, 1991), calories and alcohol, increasing physical activity and exercise, and smoking cessation (Kaplan, 1998e).

For those patients who cannot lower their blood pressures with lifestyle modification alone, pharmacologic therapy is necessary. There are more than 50 antihypertensive pharmacologic agents. These can be divided into major classes. The five major classes include (Kaplan and Gifford, 1996): diuretics, beta-blockers, calcium channel blockers ( $\mathrm{CCB}$ ), angiotensin converting enzyme inhibitors (ACE inhibitors), and alpha-blockers. The prescription of these five classes is the focus of this study.

Diuretics lower blood pressure by decreasing blood volume through the elimination of sodium and water in the kidneys. They have the advantages of lower cost and have been demonstrated to reduce long term consequences of hypertension (JNC 6). The potential disadvantages include hypokalemia, hyponatremia, hypomagnesemia, hyperuricemia, hypercalcemia, hyperlipidemia, glucose intolerance/insulin resistance, impotence, and orthostasis (Kaplan and Gifford, 1996).

Beta blockers lower blood pressure by decreasing the heart rate and 
the force of contraction. They are advantageous for people with known coronary artery disease since they have antianginal and antiarrhythmic effects. The antianginal effects can reduce symptoms of ischemia. Beta blockers prevent sudden death in patients who have had myocardial infarction (Hennekens, Albert, Godfried et al, 1996). They have been demonstrated to reduce long term consequences of hypertension. Their disadvantages include side effects of insomnia, depressed mood, exercise intolerance, impotence, and dyslipidemia. They can be particularly harmful to people with comorbid congestive heart failure or asthma (Kaplan, 1998a).

Calcium channel blockers lower blood pressure by relaxing the muscles in the arterial walls. They have advantages in their relatively benign side effect profiles and can relieve symptoms of angina but have not been demonstrated to reduce long term consequences of hypertension. They may cause constipation, headaches, flushing, and ankle edema. Some calcium channel blockers (those that decrease myocardial contractility) can be harmful in congestive heart failure (Kaplan, 1998a).

Angiotensin converting enzyme inhibitors ( $A C E$ inhibitors) prevent the formation of angiotensin, which has powerful vasoconstricting properties. This mechanism lowers the blood pressure by dilating the blood vessels. These agents have the advantages of being well tolerated and are particularly beneficial to people with heart failure, renal damage (particularly diabetic nephropathy), and post myocardial infarction. However, they have not been demonstrated to reduce the long-term consequences of hypertension alone. 
The most common side effect is a dry cough (Kaplan, 1998a).

Alpha blockers lower blood pressure by inhibiting vasoconstrictive nerve impulses. They have the advantages of a relatively benign side effect profile and can reduce symptoms of prostate disease. They have not been demonstrated to reduce long term consequences of hypertension. They can cause severe orthostasis in the elderly and may cause urinary incontinence in women.

Selection of Antihypertensive Agents

The treatment of hypertension has been extensively studied and periodic evidence-based recommendations are made. The Joint National Committee on Prevention, Detection, Evaluation, and Treatment of High Blood Pressure (JNC) issues these recommendations every four to five years. The recommendations from the last two reports have been used in this study for reasons cited above. In summarizing the recommendations pertinent to this study the following points must be made: 1) the JNC VI largely upheld the recommendations of the JNC V, as they relate to this study; 2) the reports recommend that diuretics and beta blockers should be used as first line agents because they have been proven to reduce morbidity and mortality; and 3) drug therapy should be tailored to the individual needs of patients taking into consideration such factors as age, race, comorbid conditions, lifestyle, and economic status. The effect of comorbid conditions on the selection of hypertensive classes is the primary subject of this study. Some examples were alluded to in the description of the five major classes, above. Important 
comorbid conditions that were selected for this study include: dyslipidemia, coronary artery disease, congestive heart failure, diabetes mellitus, renal failure, prostatic hypertrophy, and chronic obstructive pulmonary disease. Age and gender are potentially important demographic variables that should influence class selection (JNC 5, JNC 6, Kaplan, 1998a).

Despite the recommendations of the JNC it has been demonstrated that $\mathrm{CCB}$ and $\mathrm{ACE}$ inhibitor prescribing are increasing while diuretic and betablocker prescribing are decreasing (Kaplan, 1994, Siegel and Lopez, 1997). Until very recently (Mehta, Wilcox, and Schulman, 1999), published studies had not been able to associate prescribing with disease states that should influence selection of particular classes of agents. This study will address this important gap in the literature.

Therapeutic class associations with comorbidities can be divided into three categories: compelling indication for use; may have favorable effect on comorbidity; and, may have unfavorable effect on comorbidity (JNC 6). The first two categories can be considered preferred agents. The third category can be considered less preferred agents. Preferred agents should be expected to be used for the treatment of hypertension in patients with the given comorbidity or demographic risk factor more often than for the treatment of hypertension in patients without the comorbidity or risk factor. Less preferred agents should be expected to be used for the treatment of hypertension in patients with the given comorbidity or demographic risk factor less often than for the treatment of hypertension in patients without the 
comorbidity or risk factor. The relationships should be strongest where compelling indications exist.

Measurement Methodology

Administrative claims data have been recommended as an appropriate source for pharmacoepidemiologic research and specifically for the purposes of measuring health care quality (lezzoni, 1997; Quam et al, 1993). The advantages of using this source of data include: 1) data collection costs are relatively low since the data are already available in electronic form; 2 ) studies using these data are unobtrusive to providers and patients; 3 ) the claims database can provide a population-based, longitudinal record, across treatment sites; and 4) these data are not adversely influenced by patient recall biases. The disadvantages include: 1) diagnosis and treatment information may be incomplete; 2 ) the validity of data elements is often not well established; and 3) the data were not collected primarily for the purpose of study.

Claims data have been used to identify patients with hypertension and the validity of this method of measurement has been studied and compared to other methods of identification (Quam et al, 1993). Investigators looked at 3 methods of claims based identification and compared them with chart review and patient survey data. The study population consisted of patients from two independent practice association health plans that contracted with independent practitioners who billed discounted fee-for-service to the plans. The two study years were calendar years 1988 and 1989 . For all three 
methods, patients with specific comorbidities were excluded from analysis. The first claims based method focused specifically on diagnosis codes, the second utilized pharmacy claims, and the third method used a combination of pharmacy and diagnosis data. The diagnosis-based definition required at least one claim within a two year time period using any of ICD-9-CM codes $401,401.0,401.1$ or 401.9 and specifically excluded those with pharmacy claims for antihypertensive medications. The pharmacy-based definition required at least one prescription for an antihypertensive agent without any diagnosis codes (above) for hypertension. These two sets of criteria were designed to be mutually exclusive and to identify patients without specific comorbidities. The combined definition required both a diagnosis code and a claim for an antihypertensive agent. Patients were classified as hypertensive by the survey method if they answered positively when asked if a doctor ever told them that they have hypertension or high blood pressure. Patients were classified as hypertensive by the medical chart review method if they: (1) had hypertension or a synonym listed as a current or historical problem; (2) they had two measured elevated blood pressure readings recorded on the most recent office visits; or (3) antihypertensive therapy was listed and there was at least one recorded measurement of elevated blood pressure. Initial analysis revealed approximately $50 \%$ agreement between the diagnosisbased and prescription-based definitions and both the medical record-based and survey-based definitions. The diagnosis-based definition, when modified to require two diagnosis codes in the time interval, performed much better, 
agreeing with medical record-based definition almost $75 \%$ of the time.

The use of administrative medical claims data has been compared with a survey methodology in the identification of patients with diabetes mellitus and heart disease (O'Connor, Rush, Pronk, and Cherney, 1998). These investigators found that 2 codes for diabetes mellitus in a 2 -year period yielded a sensitivity and specificity of 0.91 and 0.99 respectively with a positive predictive value of 0.94 . For heart disease these investigators looked for one code in a defined one-year period of time. This strategy yielded sensitivity, specificity, and positive predictive values of $0.89,0.99$, and 0.85 respectively. The heart diseases that were of interest in this study included congestive heart failure, history of myocardial infarction, angina, and arteriosclerotic cardiovascular disease. It was recognized from previous work that in diabetes mellitus, a one code requirement leads to false identification of patients.

Use of administrative claims data, has typically been used in the inpatient setting (lezzoni, 1997) but has been increasingly used in the ambulatory setting. Pharmaceutical therapy prescribing was studied using a similar measurement methodology for ambulatory patients with diabetes mellitus (Glauber and Brown, 1992).

The results of these studies were used to determine the strategy used in the current study. It was decided that two codes would operationally define hypertension and the relevant comorbidities since false positive rates can be high with a one code requirement. It was anticipated that the associated decrease in sensitivity and potential decrease in sample size would not be a 
problem using the large population covered by the database that was acquired for this study.

\section{Hypotheses}

In incident uncomplicated cases of hypertension specific comorbidities should influence the prescribing of antihypertensive drug classes. Positive associations should be observed between ACE inhibitors and diuretics in congestive heart failure and between beta-blockers and CCBs in coronary artery disease. ACE inhibitors should be positively associated with diabetes mellitus and renal insufficiency, particularly in diabetic nephropathy. Alpha blockers should be positively associated with benign prostatic hypertrophy. Negative associations should be observed between beta-blockers in chronic obstructive puimonary disease, congestive heart failure, diabetes mellitus, and dyslipidemia. Negative associations should be observed for CCBs in congestive heart failure and diuretics in dyslipidemia.

In incident cases of uncomplicated hypertension without relevant comorbidities (congestive heart failure, coronary artery disease, chronic obstructive pulmonary disease, diabetes mellitus, renal insufficiency, dyslipidemia, and benign prostatic hypertrophy) diuretics and beta-blockers should be prescribed as first line agents. 


\section{METHODS}

\section{$\underline{\text { Research Design }}$}

The study employs a nonconcurrent cohort research design to test hypotheses concerning class prescribing in the presence and absence of relevant comorbidities. This longitudinal design focuses on prescribing that occurs only after the diagnoses of relevant comorbidities have been made.

\section{Patient Population}

Data for analysis were obtained from the claims database of a large Blue Cross and Blue Shield plan through a contract with the nonprofit Hawaii Medical Service Association Foundation'. This plan is the largest provider of health care coverage in the state of Hawaii. Of the 1.1 million insured in Hawaii this plan covers $53 \%$. Hawaii's population is ethnically diverse. Roughly a third of the population is white, over $60 \%$ are Asian or Pacific islander. The remaining $5 \%$ are split among black, American Indian, and other races. Of the Asian or Pacific Islanders, over $22 \%$ are Japanese, over $15 \%$ are Filipino, over $12 \%$ are Hawaiian, and over $6 \%$ are Chinese. The remaining $7.5 \%$ are split among Korean, Vietnamese, Samoan, and other. Over $7 \%$ of the population living in Hawaii are of Hispanic origin. The health system in Hawaii is similar to that of other US states with two important exceptions: 1) health care coverage in Hawaii is nearly universal since employers are required to provide coverage to all half-time and full-time

\footnotetext{
${ }^{1}$ The HMSA Foundation is a private grantmaking charity affiliated with HMSA. Its primary activities include grantmaking, research, education and community service publications.
} 
employees; and 2) there is almost no migration beyond the islands (Hawaii Medical Services Association Foundation, 1995). These characteristics make this population particularly useful for epidemiological study. Potential cases for study included patients in the fee-for-service plan with a diagnosis of hypertension at any time during calendar years 1994 through 1996.

\section{Database}

The Blue Cross and Blue Shield database included three files: the pharmacy file, the medical file, and the demographics file. These files were linked using an unique patient identification code without revealing the actual identity of individuals.

Pharmacy claims data included individual drug generic names, therapeutic class codes, dispense date, supply, and units. Generic names and therapeutic class codes from the pharmacy file were used to identify therapeutic class utilization. A patient was classified to have used the therapeutic class if he/she received an agent from that class at least once during the study interval; cases in which the first occurrence of class prescribing preceded the first date of diagnosis were eliminated. Medical claims data included diagnosis codes, procedure codes, dates of service, place of service, provider and specialty identifiers. ICD-9 CM codes (HCFA, 1994) from the medical claims file were used to determine the presence of hypertension and target comorbidities (Table 1). The demographics file included birth date, gender, dates in the plan, and type of plan.

The data were obtained in flat file format, however, the size of the data 
base required normalization. This was accomplished in Microsoft Access for Windows 95 , Version 7.0. Preliminary data cleaning and initial univariate analyses were performed using Microsoft Access prior to univariate, bivariate, and multivariate statistical analyses being performed using the SAS System for Windows, Release 6.11. Output from SAS analyses were manually entered into Microsoft Excel spreadsheets for additional manipulation and display. The results of Excel analyses appear in tables in the body of the text. Data Cleaning

Patients without any ICD-9 CM code for hypertension were eliminated. Range checks were performed on age, gender, and visit frequency. Nonsense values on these variables were identified and associated patients eliminated from analyses. In addition, a gender by diagnosis search was performed to identify any potential erroneous combinations (e.g. women with benign prostatic hypertrophy). Those identified (11 cases) were also eliminated from analyses. Frequencies of diagnoses over time and prescription use over time were used to evaluate for inconsistencies in the database.

\section{Disease Definitions}

Prevalent cases of hypertension and relevant comorbidities were operationally defined by the presence of two or more codes from a target set of ICD-9 CM codes, specific to hypertension or the relevant comorbidity, in a given patient, on two or more visits, within the three calendar years 19941996. These target sets of codes appear in Table 1. Incident cases of 
uncomplicated hypertension were operationally defined in the same manner with an additional requirement that they have a one-year period free of antihypertensive drug therapy prior to the index diagnosis and that they have no coded complications of hypertension. The index diagnosis is defined as the first appearance of a target diagnostic code within the three calendar years. A subset of cases for the incident, uncomplicated cases of hypertension were identified who had no defined relevant comorbidities. This subset were chosen to look at class prescribing in the groups of patients most likely to be following the JNC recommendations for first line therapy in uncomplicated hypertension.

Alternative strategies for operationally defining prevalent cases were explored. The effects of these strategies on potential sample sizes are summarized in Appendix A.

\section{Pharmacologic Class Definitions}

A patient was classified as having been prescribed a pharmacologic class if there was at least one appearance of a drug from that class in the pharmacy file. The first date of fill for an agent in each class was identified. Those dates were used to determine the order of class prescribing in the treatment regimens. When combination agents were used or two classes were initiated on the same date, both classes were assigned that order in the regimen. The first date of fill for each class was used to establish the temporal relationship between diagnoses of relevant comorbidities and the prescribing of classes predicted to be influenced by those diagnoses. In bivariate analyses, cases in 
which the first occurrence of class prescribing preceded the first date of diagnosis were eliminated. The presence of comorbidities and pharmacologic classes were coded as one. Their absence was coded as zero.

\section{Univariate Analyses}

Frequencies were obtained for ICD-9 CM codes, unique patients with ICD-9 CM codes, unique patients with specific comorbities, unique patients dispensed specific pharmacologic agents, and unique patients dispensed pharmacologic classes. A patient was classified as having been dispensed the class if there was at least one prescription filled from that class in the period of investigation, regardless of when that occurred.

Bivariate Analyses

Bivariate analyses were performed using $2 \times 2$ tables from the FREQ procedure in SAS Version 6 (SAS, 1995) to evaluate the associations of the relevant comorbities with the dispensing of pharmacologic agents using Chisquare and Fisher's exact test. in order to ensure that comorbidities were known prior to the prescribing decision, only cases in which the relevant comorbidities preceded prescribing of the associated classes were included in this set.

\section{Multivariate Analyses}

Backward elimination logistic regression analyses (SAS, 1995b) were performed to evaluate the independent effects of comorbidities and demographic risk factors on the dispensing of specific drug classes. The modeis for these logistic regression analyses used diuretic (DI), beta blocker 
(BB), calcium channel blocker ( $\mathrm{CCB}$ ), angiotensin converting enzyme inhibitor ( $A C E I)$, and alpha blocker $(A B)$ as outcome variables and used age, sex, and diagnosis of congestive heart failure (CHF), dyslipidemia (LIP), coronary antery disease (CAD), chronic obstructive pulmonary disease (COPD), benign prostatic hypertrophy $(\mathrm{BPH})$, diabetes mellitus (DM), and renal failure (KID) as predictor variables. All nine predictor variables were entered into the model before backward elimination of variables with significance levels greater than 0.01 . This conservative significance level was chosen because of the large number of observations and to compensate for the use of multiple models. The logistic regression models appear below.

Model 1: $\quad$ DI=CHF LIP BPH CAD COPD DM KID Age Sex Model 2: $\quad B^{*}=$ LIP BPH CAD COPD DM KID Age Sex Model 3: $\quad$ CCB $=$ CHF LIP BPH CAD COPD DM KID Age Sex Model 4: $\quad$ ACEI $=$ CHF LIP BPH CAD COPD DM KID Age Sex Model 5: $\quad \mathrm{AB}^{*}=$ LIP BPH CAD COPD DM KID Age Sex

* The beta blocker and alpha blocker models failed to converge. CHF was eliminated due to the small numbers of observations in these two models 


\section{RESULTS}

The results of univariate, bivariate, and multivariate analyses performed using SAS were manually transferred into Microsoft Excel for additional calculations and display. These results are summarized in tabular form in the body of the text.

\section{Univariate Analyses}

A total of 32,322 cases met the definition of prevalent hypertension. Of those, 4,871 met the definition of incident, uncomplicated hypertension. Of the 4,871 cases with incident, uncomplicated hypertension, 2,405 had no relevant comorbidities

The frequencies and proportions of cases with demographic characteristics and relevant comorbidities within the prevalent cases of hypertension and the incident, uncomplicated cases of hypertension appear in Table 2. Frequencies and proportions of individuals dispensed specific drug classes appear in Table 3.

Of the cases with no relevant comorbidities (Table 4) $58.8 \%$ did not fill a prescription for antihypertensive pharmacotherapy. Of those filling a prescription for antihypertensive pharmacotherapy, almost two thirds were treated with one class of therapy alone. Less than one fourth received either a diuretic or a beta-blocker as the lone therapeutic class. Over $40 \%$ received another lone therapeutic class. Diuretics and beta-blockers were each prescribed as the first class in therapy almost $20 \%$ of the time. Calcium 
channel blockers and ACE Inhibitors were each prescribed as the first class in therapy approximately $30 \%$ of the time. Alpha-blockers were prescribed as the first class in therapy less than $2 \%$ of the time.

The order of therapeutic class in the treatment regimens is displayed in Table 5. Among cases with any comorbidies, the first class in the regimen was most frequently a calcium channel blocker $(32 \%)$ followed by ACE inhibitors $(29 \%)$, diuretics $(18 \%)$, beta blockers $(17 \%)$, and alpha blockers $(3 \%)$. The second class in the regimen was most frequently an ACE inhibitor (30\%) followed by caicium channel blockers and diuretics (each at $25 \%$ ), beta blockers $(19 \%)$, and alpha blockers $(2 \%)$. Diuretics were the most commonly prescribed third line agents ( $32 \%$ ) followed by ACE inhibitors and calcium channel blockers (each at $26 \%$ ), beta blockers $(11 \%$ ), and alpha blockers $(5 \%)$. Fourth line therapy occurred very infrequently.

Among cases with no comorbidities, first line therapies were most frequently calcium channel blockers $\langle 31 \%$ ), followed by ACE inhibitors $(29 \%)$, diuretics and beta blockers (each at $19 \%$ ), and alpha blockers $(2 \%)$. Second line therapy was most commonly an ACE inhibitor ( $28 \%$ ), followed by calcium channel blockers $(27 \%)$, diuretics $(26 \%)$, beta blockers $(18 \%)$, and alpha blockers $(2 \%)$. Third line therapy was most commonly an ACE inhibitor or diuretic (each at $29 \%$ ), followed by calcium channel blockers $(26 \%)$, beta blockers $(10 \%)$, and alpha blockers $(6 \%)$.

In benign prostatic hypertrophy, alpha blockers were prescribed as first line therapy in $23 \%$ of cases but ranked only third behind calcium channel 
blockers and ACE inhibitors (each at 26\%). Beta blockers were first line therapy in $13 \%$ of cases followed by diuretics $(12 \%)$. Second, third, and fourth line therapies were infrequent.

In chronic obstructive pulmonary disease, calcium channel blockers were the class most frequently prescribed as first line therapy (32\%) followed by ACE inhibitors (30\%), diuretics (22\%), beta blockers (10\%), and alpha blockers (5\%). As second line therapy ACE inhibitors were most frequently prescribed (35\%) followed by calcium channel blockers $(29 \%)$, diuretics $(19 \%)$. beta blockers (14\%), and alpha blockers ( $4 \%)$. Third and fourth line therapies were infrequent.

Congestive heart failure was an infrequent comorbidity. Diuretics were used most commonly as first line therapy (55\%) followed by ACE inhibitors (32\%) and calcium channel blockers (14\%).

In coronary artery disease, calcium channel blockers were the class most frequently prescribed as first line therapy ( $42 \%$ ) followed by beta blockers (26\%), ACE inhibitors (21\%), diuretics $(9 \%)$, and alpha blockers $(2 \%)$. Second line therapy was most frequently a beta blocker $(42 \%)$ followed by calcium channel blockers (35\%) and ACE inhibitors $(23 \%)$. Third and fourth line therapies were infrequent.

In dyslipidemia, calcium channel blockers were the most frequently prescribed first line therapy (33\%) followed by ACE inhibitors ( $30 \%)$, diuretics $(18 \%)$, beta blockers $(15 \%)$, and alpha blockers $(4 \%)$. ACE inhibitors were the most commonly prescribed second line therapy $(32 \%)$ followed by diuretics 
(23\%), caicium channel blockers and beta blockers (each at $22 \%$ ), and alpha blockers $(2 \%)$. Third line therapy was most frequently a calcium channel blocker ( $34 \%$ ) followed by diuretics (31\%), ACE inhibitors ( $20 \%$ ), beta blockers $(9 \%)$, and alpha blockers $(6 \%)$.

In diabetes mellitus ACE inhibitors were the most frequently prescribed first line therapy ( $46 \%$ ) followed by calcium channel blockers (32\%), diuretics (27\%), and beta blockers (9\%). ACE inhibitors were also most commonly prescribed as second line therapy (29\%) followed by calcium channel blockers $(27 \%)$, diuretics $(24 \%)$, beta blockers $(15 \%)$, and alpha blockers $(6 \%)$.

Renal insufficiency was an infrequent comorbidity. ACE inhibitors were most commonly prescribed as first line therapy ( $40 \%$ ) followed by diuretics (35\%), calcium channel blockers (15\%), beta blockers and alpha blockers (each at $5 \%$ ).

\section{Bivariate Analyses}

Unadjusted Risk Ratios (RR) and 95\% Confidence Intervals (Cl) for selected bivariate relationships are displayed in Table 6 . Statistically significant RRs are evident where Cls do not include one.

Beta-blocker prescribing was positively associated with coronary artery disease and negatively associated with chronic obstructive pulmonary disease, diabetes mellitus and dyslipidemia. Of the cases with coronary artery disease, more than $22 \%$ filled a prescription for a beta blocker while those without coronary artery disease filled such a prescription less than $9 \%$ of the 
time. These proportions yielded a risk ratio of 2.56 with a $95 \%$ confidence interval of $1.85-3.56$. Of the cases with chronic obstructive pulmonary disease less than $5 \%$ filled a prescription for a beta blocker while almost $10 \%$ of cases without chronic obstructive pulmonary disease filled such a prescription. These proportions yielded a RR of 0.47 with $\mathrm{Cl} 0.31-0.71$. Less than $5 \%$ of patients with diabetes mellitus filled a prescription for a beta blocker while almost $10 \%$ without diabetes filled such a prescription. These proportions yielded a RR of 0.44 with $\mathrm{Cl} 0.28-0.67$. Cases with dysipidemia filled a prescription for a beta blocker $6 \%$ of the time while those without dyslipidemia filled such a prescription almost $10 \%$ of the time. These proportions yielded RR 0.62 with $\mathrm{Cl} 0.50-0.77$.

Coronary artery disease was also positively associated with calcium channel blocker prescribing. Cases with coronary artery disease filled prescriptions for beta blockers more than $27 \%$ of the time while those without coronary artery disease filled such prescriptions less than $16 \%$ of the time. These proportions yielded RR 1.77 with $\mathrm{Cl} 1.33-2.36$.

ACE Inhibitor prescribing was positively associated with diabetes mellitus and renal failure. ACE inhibitor prescriptions were filled by patients with diabetes mellitus in over $20 \%$ of cases. Less than $15 \%$ of cases without diabetes mellitus filled such prescriptions. These proportions yielded RR 1.41 with $\mathrm{Cl} 1.17-1.70$. ACE inhibitor prescriptions were filled by patients with renal failure in more than $28 \%$ of cases. Less than $16 \%$ of cases without renal failure filled such a prescription. These proportions yielded RR 1.84 with $\mathrm{Cl}$ 


\section{$1.11-3.04$}

Like beta blockers, diuretics were negatively associated with dyslipidemia. Less than $8 \%$ of cases with dyslipidemia filled a prescription for a diuretic while more than $11 \%$ of those without dyslipidemia filled such a prescription. These proportions yielded RR 0.69 with $\mathrm{Cl} 0.58-0.83$.

Congestive heart failure was positively associated with diuretic prescribing. Almost half of the cases with congestive heart failure filled a prescription for a diuretic while slightly more than $10 \%$ of those without congestive heart failure filled such a prescription. These proportions yielded a risk ratio $(\mathrm{RR})$ of 4.58 with a $95 \%$ confidence interval $(\mathrm{Cl})$ of 2.83-7.42. Benign prostatic hypertrophy was positively associated with alpha-blocker prescribing Almost $9 \%$ of cases with benign prostatic hypertrophy filled a prescription for an alpha blocker while only $1 \%$ without benign prostatic hypertrophy filled such a prescription. The relationships between congestive heart failure and diuretics and between alpha blockers and benign prostatic hypertrophy, although statistically significant, have questionable validity due to small cell sizes.

\section{Multivariate Analyses}

Multivariate Adjusted Odds Ratios (OR) and Confidence Intervals (CI) from logistic regression analyses appear in Table 8 . In the diuretic model, congestive heart failure (10.87 OR, 4.70-25.15 Cl) and female gender $(0.55$ OR, 0.45-0.66 Cl) were positively associated.

In the calcium channel blocker model, only coronary artery disease was 
positively associated (2.70 OR, $1.88-3.86 \mathrm{Cl}$ ). In the ACE Inhibitor model both congestive heart failure (5.88 OR, 2.57-13.43 CI) and diabetes mellitus (1.73 $R R, 1.38-2.16)$ were positively associated.

The beta blocker and alpha blocker models failed to converge with all nine variables entered initially. Because of the small numbers of congestive heart failure cases (23) this variable was eliminated from the beta blocker and alpha blocker models. Chronic obstructive pulmonary disease $(0.50 \mathrm{OR}, 0.33$ $0.75 \mathrm{Cl})$, diabetes mellitus $(0.56 \mathrm{OR}, 0.38-0.82 \mathrm{Cl})$, and male gender $(0.64$ OR, $0.52-0.78 \mathrm{Cl}$ ) were negatively associated with beta blocker prescribing while coronary artery disease was positively associated (4.39 OR, 2.93-6.56 C). Benign prostatic hypertrophy $(6.02 \mathrm{OR}, 3.50-10.36 \mathrm{Cl})$, older age $(0.39$ $\mathrm{OR}, 0.20-0.75 \mathrm{Cl})$, and male gender $(2.33 \mathrm{OR}, 1.26-4.30 \mathrm{Cl})$ were positively associated with alpha blocker prescribing. 


\section{DISCUSSION}

This section will start with a discussion of the hypotheses and systematically progress from review and comments on the results of the specific analyses, through explanations of findings consistent with, and findings seemingly inconsistent with, predicted directional relationships. Limitations and practical applications will round out the discussion. Recommendations will be made regarding future measurement efforts and opportunities for improvement in antihypertensive class selection will be identified.

Predictions were based on the assumption that preferred agents would be associated with positive risk factors and less preferred agents would be associated with negative risk factors in confirmatory bivariate analyses. The positive risk factors should have Risk Ratios greater than one. The negative risk factors should have Risk Ratios less than one. The confidence intervals for these measures of association should not include one. Significant positive relationships should be observed for the following: ACE inhibitors and diuretics in congestive heart failure, ACE inhibitors in diabetes mellitus and renal failure, beta-blockers and CCBs in coronary artery disease, and alpha-blockers in benign prostatic hypertrophy. Significant negative relationships should exist for the following: beta-blockers in chronic obstructive pulmonary disease, congestive heart failure, dyslipidemia, and diabetes mellitus, CCBs in congestive heart failure, and diuretics in dyslipidemia.

Since beta-blockers and diuretics are preferred for uncomplicated 
hypertension we should observe a higher proportion of prescribing of these agents than CCBs and ACE Inhibitors in cases without relevant comorbidities. Predicted significant positive relationships were observed for diuretic and ACE inhibitor prescribing in congestive heart failure, beta-blocker and CCB prescribing in coronary artery disease, and ACE inhibitor prescribing in diabetes mellitus and renal failure. Predicted significant negative relationships were observed for beta-blocker prescribing in diabetes mellitus, chronic obstructive pulmonary disease, and dyslipidemia. Alpha blockers were positively associated with benign prostatic hypertrophy but in both the bivariate and logistic regression models the validity of this finding is questionable due to small numbers of observations. ACE Inhibitors and diuretics were found to be positively associated with congestive heart failure in the logistic regression model but not in the bivariate analyses.

Predicted negative relationships that were not observed include betablocker and CCB prescribing in congestive heart failure. The absence of the predicted observations in congestive heart failure may be partially due to the availability of new drugs in these classes that are potentially beneficial in this disease. In addition, there were few observations in these comorbidities such that interpretation of findings within these conditions is difficult.

In the cases with no relevant comorbidities, treated with pharmacotherapy, only one quarter were treated with diuretics or betablockers as the lone class of therapy. Other lone classes of therapy were prescribed in $40 \%$ of these cases. When looking at first class in the 
therapeutic regimen, $\mathrm{CCBs}$ and $\mathrm{ACE}$ Inhibitors account for $60 \%$ while diuretics and beta blockers account for only $40 \%$. Adherence to guidelines would have been demonstrated by greater prescribing of the preferred classes than the unpreferred classes.

There were a number of interesting findings from the order of therapeutic class data. Calcium channel blockers and ACE inhibitors appear to be preferred over diuretics and beta blockers as first line therapy. That preference does not appear to depend greatly upon the presence of comorbidities. The cases without relevant comorbidities do receive beta blockers and diuretics more frequently than the cases with comorbidities however the difference is very small (1-2\%). Diuretics are used in increasing proportions as the number of classes in the regimen increases. This is true for both cases with and cases without comorbidities. Alpha blockers are infrequently prescribed and appear to have a significant role only in first line therapy for men with benign prostatic hypertrophy. Even in that group, ACE inhibitors and calcium channel blockers are prescribed more frequently than alpha blockers. Beta blockers appear less frequently as first line therapy in chronic obstructive pulmonary disease and diabetes mellitus than in cases without comorbidities. ACE inhibitors seem to be preferred in renal insufficiency and diabetes mellitus.

\section{Limitations}

This measurement model was able to confirm the vast majority of the predicted associations. However, potential applications of these results must 
be weighed against important methodological and theoretical limitations.

The use of administrative claims data is advantageous because they are relatively inexpensive and unobtrusive to obtain. However, an important limitation of using the automated health plan databases for research is the lack of information on potential confounders. In prescribing for hypertension these potential confounders include: race, patient preference, and history of previous therapeutic trials. In this study the effect of history of previous therapeutic trials was addressed by creating the ideal group of incident, uncomplicated cases of hypertension. Race and patient preferences were not accessible in this data base.

Another potential limitation stems from the reliance on dispensing data for attribution of prescribing practices. Prescribing could have occurred but if the patients did not fill the prescriptions then the prescribing was not counted. In the present study, $58 \%$ of incident, uncomplicated cases with no relevant comorbidities did not fill any prescriptions for antihypertensive therapy. It is not known how many of these had prescriptions given and not filled or prescriptions not given. It is also important to recall that not all hypertension needs to be treated with pharmacotherapy. A trial of lifestyle modification is suggested, prior to instituting pharmacotherapy. This study dealt with this potential limitation by focusing primarily on the patients who used pharmacotherapy. There should only be a problem in interpreting relative prescribing of classes if patients were less likely to fill prescriptions for some classes compared to others. This question is beyond the scope of this 
investigation.

Another potential limitation has to do with the generalizability of the findings to other populations. Hawaii is different from other states in its relative geographic isolation and in the racial and ethnic composition of its population. These differences should not influence prescribing practices since the same risks and benefits apply to the different races and ethnic groups. There may however, be a cultural difference in the filling of prescribed therapies. If Hawaiians are less likely to fill prescriptions than Americans in other states then the magnitudes of proportions would be lower in this study than if studied in the continental United States. The relative measures of prescribing should not be influenced by such a cultural difference however. Future studies should attempt to measure these effects in other states and in other practice and payer models.

Another potential limitation of this study stems from the use of multiple tests and comparisons. This strategy can lead to the identification of spurious relationships. These finding should be confirmed in an independent sample.

It is also worth noting that the alpha blocker and beta blocker logistic regression models did not converge until congestive heart failure was removed. The decision to remove congestive heart failure from these models was based upon the small number of cases with congestive heart failure. This is not surprising given that hypertension is a major risk factor for congestive heart failure and there should be very little congestive heart failure in a population with incident hypertension. Since the calcium channel blocker, 
ACE inhibitor, and diuretic models did converge with congestive heart failure included, this condition was not removed from these models. It was particularly important to look at congestive heart failure in the diuretic and ACE inhibitor models since this condition is considered a compelling indication for the use of these classes of therapy.

Coded claims can introduce a potential systematic bias in classification of comorbidities and drug prescribing. The use of a diagnostic code can be made in error and the filling of a prescription can be made in error. By insisting on at least two codes for the definition of comorbidities this study should have reduced the probability of falsely including cases with the relevant comorbidities. By accepting any dispensing of an antihypertensive agent as defining the prescribing this study could have falsely identified some class prescribing. Future investigations should explore the use of other drug prescribing definitions

\section{Measurement Issues}

The measurement strategy used in this study was sufficient to demonstrate expected relationships among comorbidities and antihypertensive classes. Subsets of comorbidities should have more specificity and therefore might show larger effect sizes. Future studies should explore the use of more specific subsets (e.g. left heart failure, diabetic nephropathy) in a larger population (e.g. prevalent cases of hypertension). A structural model could incorporate known causal relationships among diseases, demographic and therapeutic variables. It might also be useful to look at specialist-generalist 
comparisons and high volume provider-low volume provider comparisons to further validate the measures.

\section{Practical Applications}

The study examined the association between population-based, plan level, antihypertensive prescribing and comorbidities. Compelling indications appear to influence prescribing as do conditions for which there may be favorable or unfavorable effects of certain classes of agents. It can also be safely stated that diuretics and beta-blockers are not treated as preferred agents in uncomplicated hypertension as recommended.

Opportunities For Improvement in Prescribing

Opportunities for improvement in prescribing can be classified as problems of underutilization or overutilization. Since the JNC continues to recommend diuretic and beta-blockers as first line agents for uncomplicated hypertension we need to look at the relative utilization of these agents compared to other classes. These preferred classes rank third and fourth behind CCBs and ACE inhibitors. This can be interpreted as underutilization of these preferred classes or overutilization of the more popular but less preferred (according to evidence/guidelines) classes for the treatment of uncomplicated hypertension. The second area to look at relates to what the JNC is now calling compelling indications. These compelling indications are based upon randomized controlled clinical trials and were the source of many of the predicted relationships in this study. These compelling indications include: $A C E$ inhibitors for diabetic nephropathy, ACE inhibitors and diuretics 
for heart failure, and beta-blockers for post myocardial infarction. The numbers of observations within these comorbidity sets was too low for meaningful quantitative conclusions. These conditions are expected to be uncommon in incident cases of uncomplicated hypertension. A future study should attempt to quantify these relationships in prevalent cases of hypertension where these important comorbidities have been demonstrated to be more prevalent (Table 2).

Conclusions

Administrative claims data can be successfully used to measure prescribing practices in hypertension. Comorbidities influence prescribing in hypertension as outlined in Joint National Commission guidelines. However, diuretics and beta blockers are not preferred over calcium channel blockers and angiotensin converting enzyme inhibitors as first line therapy in uncomplicated hypertension, despite the significant evidence base that supports this practice. 
Table 1. ICD-9 CM * code sets for operational definitions of prevalent cases of hypertension and relevant comorbidities: broad definitions

Hypertension

Patients with ICD-9 CM codes for hypertension: 401.x, 402.xx, 403.xx, 404.xx, and 405.xx

Coronary Artery Disease

Patients with ICD-9 CM codes for Myocardial Infarction, Ischemic Heart Disease Angina, or Coronary Atherosclerosis: $410 . x x, 411 . x x, 412,413 x, 414,414.0,414.8$, and 414.9

Congestive Heart Failure

Patients with ICD-9 CM codes for Heart Failure: $428 . x, 402 \times 1,404 . x 1$, and $404 . x 3$

Diabetes Mellitus

Patients with ICD-9 CM codes for Diabetes Mellitus: $250 . x x$

Chronic Obstructive Pulmonary Disease

Patients with ICD-9 CM codes for Asthma, Chronic Bronchitis, Emphysema, Bronchitis Not Specified as Acute or Chronic, and Chronic Airway Obstruction Not Elsewhere Classified: 490, 491.xx, 492.x, 493.xx, and 496.

Benign Prostatic Hypertrophy

Patients with ICD-9 CM code for BPH: 600

Dyslipidemias

Patients with ICD-9 CM codes for Disorders of Lipoid Metabolism or Hyperlipidemias: $272 . x$

Kidney Disease

Patients with ICD-9 CM codes for Renal Failure, Nephrotic or Nephritic Disorders, Hypertensive Renal Disease, or Diabetic Nephropathy: 581.x, 582.xx, 583.xx, 584.x, $585,586,587,403 . x x, 404 . x x$, and $250.4 x$

" HCFA (1994) 
Table 1. (Cont.) ICD-9 CM * code sets for operational definitions of prevalent cases of hypertension and relevant comorbidities: specific subsets

Hypertension, Uncomplicated Essential (Specific Subset of Hypertension) Patients with ICD-9 CM codes for Essential, Benign Essential, and Unspecified Essential Hypertension: 401, 401.1, and 401.9 without ICD-9 CM codes for Malignant Hypertension, Hypertensive Heart Disease, Hypertensive Renal Disease, or Secondary Hypertension: 401.0, 402.xx, 403.xx, 404.xx, and 405.xx

Hypertension, Uncomplicated Essential, Incident Cases (Specific Subset of Hypertension)

Patients classified as Uncomplicated Essential Hypertension in whom the first appearance of the ICD-9 CM code for Hypertension is preceded by a one year period free of anti-hypertensive pharmacotherapy.

Post Myocardial Infarction (Specific Subset of Coronary Artery Disease) Patients with ICD-9 CM codes for Myocardial Infarction, Post Myocardial Infarction Syndrome, or Old Myocardial Infarction: 410.xx, 411.0, and 412

Left Heart Failure (Specific Subset of CHF)

Patients with ICD-9 CM codes for Left Heart Failure: 428.1

Hypertensive Heart Disease with Congestive Heart Failure (Specific Subset of CHF) Patients with ICD-9 CM codes for Hypertensive Heart Disease with CHF: 402.x1, 404. $\times 1$ and 404.x3

Asthma (Specific Subset of COPD)

Patients with ICD-9 CM codes specific to Asthma: 493.xx

* HCFA (1994) 
Table 1. (Cont.) ICD-9 CM * code sets for operational definitions of prevalent cases of hypertension and relevant comorbidities: specific subsets

Type 1 Diabetes Mellitus (Specific Subset of DM)

Patients with ICD-9 CM codes for Diabetes Mellitus Type 1: 250.x1

Hypertensive Renal Disease (Specific Subset Kidney Disease)

Patients with ICD-9 CM codes for Hypertensive Renal Disease: 403.xx and 404.xx

Diabetic Nephropathy 1 (Specific Subset of Kidney Disease and DM)

Patients with 1 CD-9 CM codes for Diabetes Mellitus with Renal Manifestation or

Diabetes Mellitus and Chronic or Unspecified Renal Failure: 250.4x, 250.xx and (585 or 586)

Diabetic Nephropathy 2 (More Specific Subset of Kidney Disease and DM))

Patients with ICD-9 CM codes for Diabetes Mellitus with Renal Manifestations: $250.4 \mathrm{X}$

Other Renal Disease (Specific Subset of Kidney Disease)

Patients with ICD-9 CM codes for non-hypertensive and non-diabetic renal diseases: $581 . x x, 582 . x x, 583 . x x, 584 . x, 585$, and 586,587

${ }^{*}$ HCFA (1994) 
Table 2. Frequencies and (proportions) of demographics \& relevant comorbidities in prevalent cases of hypertension and incident, uncomplicated cases of hypertension

\begin{tabular}{|c|c|c|}
\hline & $\begin{array}{c}\text { Prevalent } \\
\text { Hypertension } \\
\mathrm{N}=32,322\end{array}$ & $\begin{array}{c}\text { Incident, } \\
\text { Uncomplicated } \\
\text { Hypertension } \\
\mathrm{N}=4,871\end{array}$ \\
\hline Older Age (>64) & $2548(7.9)$ & $237(4.9)$ \\
\hline Female & $15,422(47.8)$ & $2343(48.1)$ \\
\hline $\begin{array}{l}\text { Chronic Obstructive Pulmonary } \\
\text { Disease }\end{array}$ & $3695(11.4)$ & $514(10.6)$ \\
\hline Asthma & $1991(6.2)$ & $269(5.5)$ \\
\hline Benign Prostatic Hypertrophy & $2808(8.7)$ & $282(5.8)$ \\
\hline Coronary Artery Disease & $2934(9.1)$ & $141(2.9)$ \\
\hline Post Myocardial Infarction & $501(1.6)$ & $25(0.5)$ \\
\hline Dyslipidemia & $15442(47.8)$ & $1834(37.7)$ \\
\hline Congestive Heart Failure & $915(2.8)$ & $23(0.5)$ \\
\hline Left Heart Failure & $91(0.3)$ & $2(0)$ \\
\hline Hypertensive Heart Failure & $130(0.4)$ & $0(0)$ \\
\hline Diabetes Mellitus & $5936(18.4)$ & $515(10.6)$ \\
\hline Type 1 Diabetes Mellitus & $651(2.0)$ & $34(0.7)$ \\
\hline Renal Failure & $1029(3.2)$ & $41(0.8)$ \\
\hline Diabetic Nephropathy (Def 1) & $225(0.7)$ & $3(0.1)$ \\
\hline Diabetic Nephropathy (Def 2) & $398(1.2)$ & $8(0.2)$ \\
\hline Hypertensive Renal Failure & $363(1.1)$ & $0(0)$ \\
\hline Other Renal Failure & $816(2.5)$ & $38(0.8)$ \\
\hline
\end{tabular}

Diabetic Nephropathy definitions in Table 1. 
Table 3. Frequencies and (proportions) of patients dispensed drug classes in prevalent cases of hypertension and in incident, uncomplicated cases of hypertension

\begin{tabular}{|c|c|c|}
\hline $\begin{array}{c}\text { Drug } \\
\text { Class }\end{array}$ & $\begin{array}{c}\text { Prevalent } \\
\text { Hypertension } \\
(\mathrm{N}=32,322)\end{array}$ & $\begin{array}{c}\text { Incident, } \\
\text { Uncomplicated } \\
\text { Hypertension } \\
(\mathrm{N}=4,871)\end{array}$ \\
\hline Diuretic & $8346(25.8)$ & $514(10.6)$ \\
\hline Beta-Blocker & $6834(21.1)$ & $446(9.2)$ \\
\hline CCB & $13248(41.0)$ & $787(16.2)$ \\
\hline ACEI & $10683(33.1)$ & $755(15.5)$ \\
\hline Alpha-Blocker & $1430(6.7)$ & $74(1.5)$ \\
\hline ARB & $1430(4.4)$ & $143(2.9)$ \\
\hline Sympatholytic & $1447(4.5)$ & $51(1.0)$ \\
\hline Vasodilator & $381(1.2)$ & $3(0.1)$ \\
\hline
\end{tabular}

$\mathrm{CCB}=$ Calcium Channel Blocker $A C E I=$ Angiotensin Converting Enzyme Inhibitor ARB = Angiotensin II Receptor Blocker 
Table 4. Antihypertensive drug classes dispensed in incident, uncomplicated cases with no relevant comorbidities*

\begin{tabular}{|l|c|c|}
\hline & $\begin{array}{c}\text { Frequencies } \\
\text { and } \\
\text { (Proportions) } \\
\text { of Total Cases } \\
(\mathrm{N}=2405)\end{array}$ & $\begin{array}{c}\text { Frequencies and } \\
\text { (Proportions) of } \\
\text { those Dispensed } \\
\text { Antihypertensive } \\
\text { Drug(s) (N=991) }\end{array}$ \\
\hline No Drug & $1414(58.8)$ & $0(0)$ \\
\hline Diuretic & $272(11.3)$ & $272(27.4)$ \\
\hline Beta-blocker & $246(10.2)$ & $246(24.8)$ \\
\hline CCB & $390(16.2)$ & $390(39.4)$ \\
\hline ACE inhibitor & $368(15.3)$ & $368(37.1)$ \\
\hline Alpha-blocker & $68(2.8)$ & $68(6.9)$ \\
\hline Diuretic alone & $92(3.8)$ & $92(9.3)$ \\
\hline $\begin{array}{l}\text { Beta-blocker } \\
\text { alone }\end{array}$ & $129(5.4)$ & $129(13.0)$ \\
\hline CCB alone & $216(9.0)$ & $216(21.8)$ \\
\hline $\begin{array}{l}\text { ACE inhibitor } \\
\text { alone }\end{array}$ & $181(7.5)$ & $181(18.3)$ \\
\hline $\begin{array}{l}\text { Alpha-blocker } \\
\text { alone }\end{array}$ & $9(0.4)$ & $9(0.9)$ \\
\hline
\end{tabular}

\begin{tabular}{|l|l|}
\hline & $\begin{array}{l}\text { Frequencies and (Proportions) } \\
\text { as First Class in Therapy } \\
(\mathrm{N}=1027)\end{array}$ \\
\hline Diuretic & $199(19.4)$ \\
\hline Beta-blocker & $199(19.4)$ \\
\hline CCB & $319(31.1)$ \\
\hline ACE Inhibitor & $294(28.6)$ \\
\hline Alpha-blocker & $16(1.6)$ \\
\hline
\end{tabular}

* Cases with incident, uncomplicated hypertension without any of the following comorbidities: coronary artery disease, congestive heart failure, chronic obstructive pulmonary disease, dyslipidemia, diabetes mellitus, renal failure, and benign prostatic hypertrophy

** N's don't match due to 36 ties for first class in therapy. 
Table 5: Order of therapeutic class in treatment regimens in incident uncomplicated cases of hypertension

\begin{tabular}{|c|c|c|c|c|c|c|c|c|c|c|c|}
\hline & Order & Diuretic & $\begin{array}{c}\text { Beta } \\
\text { Block }\end{array}$ & & CCB & & ACEl & & $\begin{array}{c}\text { Alpha } \\
\text { Block }\end{array}$ \\
\hline & & Freq & $\%$ & Freq & $\%$ & Freq & $\%$ & Freq & $\%$ & Freq & $\%$ \\
\hline Any & 1 & 371 & 18 & 347 & 17 & 648 & 32 & 595 & 29 & 61 & 3 \\
\hline & 2 & 115 & 25 & 88 & 19 & 117 & 25 & 140 & 30 & 9 & 2 \\
\hline & 3 & 24 & 32 & 8 & 11 & 20 & 26 & 20 & 26 & 4 & 5 \\
\hline & 4 & 4 & 44 & 3 & 33 & 2 & 22 & 0 & 0 & 0 & 0 \\
\hline
\end{tabular}

\begin{tabular}{|c|c|c|c|c|c|c|c|c|c|c|c|}
\hline None & 1 & 199 & 19 & 199 & 19 & 318 & 31 & 294 & 29 & 16 & 2 \\
\hline & 2 & 61 & 26 & 43 & 18 & 63 & 27 & 65 & 28 & 4 & 2 \\
\hline & 3 & 9 & 29 & 3 & 10 & 8 & 26 & 9 & 29 & 2 & 6 \\
\hline & 4 & 3 & 60 & 1 & 20 & 1 & 20 & 0 & 0 & 0 & 0 \\
\hline
\end{tabular}

\begin{tabular}{|c|c|c|c|c|c|c|c|c|c|c|c|}
\hline BPH & 1 & 12 & 12 & 13 & 13 & 27 & 26 & 27 & 26 & 24 & 23 \\
\hline & 2 & 7 & 32 & 5 & 23 & 5 & 23 & 3 & 14 & 2 & 9 \\
\hline & 3 & 1 & 33 & 0 & 0 & 2 & 67 & 0 & 0 & 0 & 0 \\
\hline & 4 & 0 & 0 & 0 & 0 & 0 & 0 & 0 & 0 & 0 & 0 \\
\hline
\end{tabular}

Any = Any Comorbidities

None $=$ No Comorbidities

$\mathrm{BPH}=$ Benign Prostatic Hypertrophy

$\mathrm{CCB}=$ Calcium Channel Blocker

ACE $1=$ Angiotensin Converting Enzyme Inhibitor 
Table 5: Order of therapeutic class in treatment regimens in incident uncomplicated cases of hypertension

\begin{tabular}{|c|c|c|c|c|c|c|c|c|c|c|c|}
\hline & $\begin{array}{c}\text { Orde } \\
r\end{array}$ & Diuretic & $\begin{array}{c}\text { Beta } \\
\text { Block }\end{array}$ & & CCB & & ACEI & & $\begin{array}{c}\text { Alpha } \\
\text { Block }\end{array}$ \\
\hline & & Freq & $\%$ & Freq & $\%$ & Freq & $\%$ & Freq & $\%$ & Freq & $\%$ \\
\hline $\begin{array}{c}\text { COP } \\
\text { D }\end{array}$ & 1 & 43 & 22 & 20 & 10 & 63 & 32 & 59 & 30 & 10 & 5 \\
\hline & 2 & 10 & 19 & 7 & 14 & 15 & 29 & 18 & 35 & 2 & 4 \\
\hline & 3 & 3 & 30 & 0 & 0 & 1 & 10 & 5 & 50 & 1 & 10 \\
\hline & 4 & 0 & 0 & 0 & 0 & 1 & 100 & 0 & 0 & 0 & 0 \\
\hline
\end{tabular}

\begin{tabular}{|c|c|c|c|c|c|c|c|c|c|c|c|}
\hline $\mathrm{CHF}$ & 1 & 12 & 55 & 0 & 0 & 3 & 14 & 7 & 32 & 0 & 0 \\
\hline & 2 & 0 & 0 & 0 & 0 & 2 & 33 & 4 & 67 & 0 & 0 \\
\hline & 3 & 1 & 50 & 0 & 0 & 0 & 0 & 1 & 50 & 0 & 0 \\
\hline & 4 & 0 & 0 & 0 & 0 & 0 & 0 & 0 & 0 & 0 & 0 \\
\hline
\end{tabular}

\begin{tabular}{|c|c|c|c|c|c|c|c|c|c|c|c|}
\hline CAD & 1 & 8 & 9 & 24 & 26 & 38 & 42 & 19 & 21 & 2 & 2 \\
\hline & 2 & 0 & 0 & 11 & 42 & 9 & 35 & 6 & 23 & 0 & 0 \\
\hline & 3 & 3 & 50 & 0 & 0 & 0 & 0 & 3 & 50 & 0 & 0 \\
\hline & 4 & 0 & 0 & 1 & 100 & 0 & 0 & 0 & 0 & 0 & 0 \\
\hline
\end{tabular}

COPD = Chronic Obstructive Pulmonary Disease

$\mathrm{CHF}=$ Congestive Heart Faiture

$\mathrm{CAD}=$ Coronary Artery Disease

$\mathrm{CCB}=$ Calcium Channel Blocker

ACEI = Angiotensin Converting Enzyme Inhibitor 
Table 5: Order of therapeutic class in treatment regimens in incident uncomplicated cases of hypertension

\begin{tabular}{|c|c|c|c|c|c|c|c|c|c|c|c|}
\hline & Order & $\begin{array}{c}\text { Diureti } \\
\text { c }\end{array}$ & $\begin{array}{c}\text { Beta } \\
\text { Block }\end{array}$ & CCB & & ACEI & & $\begin{array}{c}\text { Alpha } \\
\text { Block }\end{array}$ & \\
\hline & Freq & $\%$ & Freq & $\%$ & Freq & $\%$ & Freq & $\%$ & Freq & $\%$ \\
\hline LIP & 1 & 128 & 18 & 108 & 15 & 235 & 33 & 212 & 30 & 31 & 4 \\
\hline & 2 & 38 & 23 & 36 & 22 & 37 & 22 & 53 & 32 & 3 & 2 \\
\hline & 3 & 11 & 31 & 3 & 9 & 12 & 34 & 7 & 20 & 2 & 6 \\
\hline & 4 & 1 & 33 & 1 & 33 & 1 & 33 & 0 & 0 & 0 & 0 \\
\hline
\end{tabular}

\begin{tabular}{|c|c|c|c|c|c|c|c|c|c|c|c|}
\hline DM & 1 & 27 & 12 & 20 & 9 & 70 & 32 & 101 & 46 & 1 & 0 \\
\hline & 2 & 13 & 24 & 8 & 15 & 15 & 27 & 16 & 29 & 3 & 6 \\
\hline & 3 & 6 & 67 & 2 & 22 & 0 & 0 & 1 & 11 & 0 & 0 \\
\hline & 4 & 0 & 0 & 1 & 100 & 0 & 0 & 0 & 0 & 0 & 0 \\
\hline
\end{tabular}

\begin{tabular}{|c|c|c|c|c|c|c|c|c|c|c|c|}
\hline KID & 1 & 7 & 35 & 1 & 5 & 3 & 15 & 8 & 40 & 1 & 5 \\
\hline & 2 & 1 & 13 & 0 & 0 & 3 & 38 & 4 & 50 & 0 & 0 \\
\hline & 3 & 0 & 0 & 0 & 0 & 0 & 0 & 1 & 100 & 0 & 0 \\
\hline & 4 & 0 & 0 & 0 & 0 & 0 & 0 & 0 & 0 & 0 & 0 \\
\hline
\end{tabular}

\footnotetext{
LIP = Dyslipidemia

DM = Diabetes Mellitus

$K I D=$ Renal Insufficiency

$\mathrm{CCB}=$ Calcium Channel Blocker

ACEI = Angiotensin Converting Enzyme Inhibitor
} 
Table 6 . Unadjusted risk ratios and confidence intervals for selected bivariate relationships in incident, uncomplicated cases of hypertension

\begin{tabular}{|l|l|l|l|l|}
\hline $\begin{array}{l}\text { Congestive } \\
\text { Heart Failure }\end{array}$ & $\begin{array}{l}\text { Proportion } \\
\text { with Risk } \\
\text { Factor on } \\
\text { Class }\end{array}$ & $\begin{array}{l}\text { Proportion } \\
\text { without } \\
\text { Risk Factor on } \\
\text { Class }\end{array}$ & $\begin{array}{l}\text { Risk } \\
\text { Ratios }\end{array}$ & $\begin{array}{l}\text { Confidence } \\
\text { Intervals } \\
(95 \%)\end{array}$ \\
\hline Diuretic & 47.37 & 10.33 & 4.58 & $\begin{array}{l}2.83-\overline{7.42} \\
+\end{array}$ \\
\hline
\end{tabular}

\begin{tabular}{|l|l|l|l|l|}
\hline $\begin{array}{l}\text { Coronary } \\
\text { Artery } \\
\text { Disease }\end{array}$ & & & & \\
\hline Beta-Blocker & 22.22 & 8.67 & 2.56 & $1.85-3.56^{*}$ \\
\hline CCB & 27.69 & 15.64 & 1.77 & $1.33-2.36^{*}$ \\
\hline
\end{tabular}

\begin{tabular}{|l|l|l|l|l|}
\hline $\begin{array}{l}\text { Diabetes } \\
\text { Mellitus }\end{array}$ & & & & \\
\hline Beta-Blocker & 4.16 & 9.53 & 0.436 & $0.28-0.67^{*}$ \\
\hline ACE Inhibitor & 20.60 & 14.62 & 1.41 & $1.17-1.70^{*}$ \\
\hline
\end{tabular}

\begin{tabular}{|l|l|l|l|l|}
\hline Renal Failure & & & & \\
\hline ACE Inhibitor & 28.21 & 15.36 & 1.84 & $1.11-3.044^{\star}$ \\
\hline
\end{tabular}

\begin{tabular}{|l|l|l|l|l|}
\hline COPD & & & \\
\hline Beta-Blocker & 4.51 & 9.62 & 0.47 & $0.31-0.71^{*}$ \\
\hline
\end{tabular}

\begin{tabular}{|l|l|l|l|l|}
\hline Dyslipidemia & & & & \\
\hline Diuretic & 7.59 & 11.06 & 0.69 & $0.58-0.83$ \\
\hline Beta-Blocker & 6.07 & 9.81 & 0.62 & $0.50-0.77$ \\
\hline
\end{tabular}

\begin{tabular}{|l|l|l|l|l|}
\hline $\begin{array}{l}\text { Benign } \\
\text { Prostatic } \\
\text { Hypentrophy }\end{array}$ & & & & \\
\hline $\begin{array}{l}\text { Alpha- } \\
\text { Blocker }\end{array}$ & 8.90 & 1.05 & 8.51 & $\begin{array}{l}5.33-13.58 * \\
+\end{array}$ \\
\hline
\end{tabular}

CCB = Calcium Channel Blocker

$\mathrm{ACE}=$ Angiotensin Converting Enzyme

COPD $=$ Chronic Obstructive Pulmonary Disease

* $\quad=$ Confidence Interval Does Not Include 1

$+\quad=\quad=$ Questionable Validity Due to Small Number of Observations 
Table 7. Adjusted odds ratios and confidence intervals from logistic regression analyses in incident, uncomplicated cases of hypertension

Diuretic Model

DI=COPD BPH CAD LIP CHF DM KID Age Sex

\begin{tabular}{|c|c|c|}
\hline Variables & Odds Ratios & $\begin{array}{c}\text { Confidence Intervals } \\
\text { (Wald, 95\%) }\end{array}$ \\
\hline CHF & 10.87 & $4.70-25.15$ \\
\hline Male & 0.55 & $0.45-0.66$ \\
\hline
\end{tabular}

Calcium Channel Blocker Model

CCB $=$ COPD BPH CAO LIP CHF DM KID Age Sex

\begin{tabular}{|c|c|c|}
\hline Variables & Odds Ratios & $\begin{array}{c}\text { Confidence Intervais } \\
\text { (Wald, 95\%) }\end{array}$ \\
\hline CAD & 2.70 & $1.88-3.86$ \\
\hline
\end{tabular}

ACE Inhibitor Model

$A C E \mid=C O P D B P H C A D$ LIP CHF DM KID Age Sex

\begin{tabular}{|c|c|c|}
\hline Variables & Odds Ratios & $\begin{array}{c}\text { Confidence interval } \\
\text { (Wald, 95\%) }\end{array}$ \\
\hline CHF & 5.88 & $2.57-13.43$ \\
\hline $\mathrm{DM}$ & 1.73 & $1.38-2.16$ \\
\hline
\end{tabular}

COPD $=$ Chronic Obstructive Pulmonary Disease

$\mathrm{CAD}=$ Coronary Artery Disease $\quad \mathrm{CHF}=$ Congestive Heart Failure

$\mathrm{BPH}=$ Benign Prostatic Hypertrophy DM = Diabetes Mellitus

$K I D=$ Renal Failure $\quad$ LIP = Dyslipidemia

Older Age $=$ Age $>64$ 
Table 7. Adjusted odds ratios and confidence intervals from logistic regression analyses in incident, uncomplicated cases of hypertension

Beta Blocker Model

$B B=C O P D$ BPH CAD LIP DM KID Age Sex

\begin{tabular}{|c|c|c|}
\hline Variables & Odds Ratios & $\begin{array}{c}\text { Confidence Intervals } \\
\text { (Wald. 95\%) }\end{array}$ \\
\hline COPD & 0.50 & $0.33-0.75$ \\
\hline CAD & 4.39 & $2.93-6.56$ \\
\hline DM & 0.56 & $0.38-0.82$ \\
\hline Male & 0.64 & $0.52-0.78$ \\
\hline
\end{tabular}

Alpha-Blocker Model

$A B=C O P D$ BPH CAD LIP DM KID Age Sex

\begin{tabular}{|c|c|c|}
\hline Variables & Odds Ratios & $\begin{array}{c}\text { Confidence Intervals } \\
(\text { Wald. 95\%) }\end{array}$ \\
\hline BPH & 6.02 & $3.50-10.36$ \\
\hline Age & 0.39 & $0.20-0.75$ \\
\hline Male & 2.33 & $1.26-4.30$ \\
\hline
\end{tabular}

COPD $=$ Chronic Obstructive Pulmonary Disease

$\mathrm{CAD}=$ Coronary Artery Disease $\quad \mathrm{CHF}=$ Congestive Heart Failure

$\mathrm{BPH}=$ Benign Prostatic Hypertrophy $\mathrm{DM}=$ Diabetes Mellitus

$K I D=$ Renal Failure $\quad$ LIP $=$ Dystipidemia

Older Age $=$ Age $>64$

* CHF eliminated from beta blocker and alpha blocker models due to small numbers of observations 
Appendix A: Alternatives for Operational Definitions of Prevalent Cases

Various operational definitions for prevalent cases were considered and tested for their effects on potential sample size. These operational definitions varied in two different dimensions: the number of required occurrences of the target ICD-9 CM codes and the duration of the interval during which codes must appear.

The first dimension varied from one code in the time interval, to two codes, to three codes. The second dimension varied in the duration of the time interval from index diagnosis date plus one year, to index diagnosis date plus two years, to the entire three calendar years. The index diagnosis date was the date on which the first diagnosis code from the respective comorbidity set appeared in the claims history.

The table (below) shows the frequencies and proportions of observations, in a $50 \%$ random sample, meeting the various comorbidity definitions for the number of codes required and duration of the interval. 
Table. Operational Definitions of Prevalent Cases of Hypertension and Relevant Comorbities, according to number of codes required and time interval for observing the codes, with frequencies and (proportions) reported $N=19,707$ from a $50 \%$ random sample

\begin{tabular}{|c|c|c|c|}
\hline $\begin{array}{c}\text { Prevalent Cases of } \\
\text { Hypertension }\end{array}$ & 3 Codes (GE) & 2 Codes (GE) & 1 Codes (GE) \\
\hline Index diagnosis + 1 yr & $11,811(59.9)$ & $14,916(75.7)$ & $19,707(100)$ \\
\hline Index diagnosis + 2 yr & $13,488(68.1)$ & $15,912(80.7)$ & $19,707(100)$ \\
\hline $1994-1996$ & $13,839(70.2)$ & $16,080(81.6)$ & $19,707(100)$ \\
\hline
\end{tabular}

\begin{tabular}{|c|c|c|c|}
\hline $\begin{array}{c}\text { Incident, } \\
\text { Uncomplicated Cases } \\
\text { of Hypertension }\end{array}$ & 3 Codes (GE) & 2 codes (GE) & 1 Codes (GE) \\
\hline index diagnosis +1 yr & $9,263(47.0)$ & $12,016(61.0)$ & $16,535(83.9)$ \\
\hline Index diagnosis +2 yr & $10,648(54.0)$ & $12,864(65.3)$ & $16,535(83.9)$ \\
\hline $1994-1996$ & $10,945(55.5)$ & $13.011(66.0)$ & $16.535(83.9)$ \\
\hline
\end{tabular}

\begin{tabular}{|c|c|c|c|}
\hline BPH & 3 Codes (GE) & 2 Codes (GE) & 1 Codes (GE) \\
\hline Index diagnosis +1 yr & $530(2.7)$ & $1,123(5.7)$ & $2,751(14.0)$ \\
\hline Index diagnosis +2 yr & $805(4.1)$ & $1,484(7.5)$ & $2,751(14.0)$ \\
\hline $1994-1996$ & $905(4.6)$ & $1,540(7.8)$ & $2,751(14.0)$ \\
\hline
\end{tabular}

\begin{tabular}{|c|c|c|c|}
\hline LIP & 3 Codes (GE) & 2 Codes (GE) & 1 Codes (GE) \\
\hline Index diagnosis $+1 \mathrm{yr}$ & $5,596(28.4)$ & $7,898(40.1)$ & $11,531(58.5)$ \\
\hline Index diagnosis $+2 \mathrm{yr}$ & $6,860(34.8)$ & $8,739(44.3)$ & $11,531(58.5)$ \\
\hline $1994-1996$ & $7,143(36.2)$ & $8,892(45.1)$ & $11,531(58.5)$ \\
\hline
\end{tabular}

\begin{tabular}{|l|l|}
\hline BPH & $=$ Benign Prostatic Hypertrophy \\
\hline LIP & $=$ Dyslipidemia \\
\hline
\end{tabular}


Table. Operational Definitions of Prevalent Cases of Hypertension and Relevant Comorbities, according to number of codes required and time interval for observing the codes, with frequencies and (proportions) reported. $\mathrm{N}=19,707$ from a $50 \%$ random sample

\begin{tabular}{|c|c|c|c|}
\hline CAD & 3 Codes (GE) & 2 Codes (GE) & 1 Codes (GE) \\
\hline Index diagnosis $+1 \mathrm{yr}$ & $1,273(6.5)$ & $1.723(8.7)$ & $2,754(14.0)$ \\
\hline Index diagnosis $+2 \mathrm{yr}$ & $1,396(7.1)$ & $1,797(9.1)$ & $2,754(14.0)$ \\
\hline $1994-1996$ & $1,428(7.2)$ & $1,812(9.2)$ & $2,754(14.0)$ \\
\hline
\end{tabular}

\begin{tabular}{|c|c|c|c|}
\hline MI & 3 Codes (GE) & 2 Codes $(\mathrm{GE})$ & 1 Codes $(\mathrm{GE})$ \\
\hline Index diagnosis + 1 yr & $223(1.1)$ & $313(1.6)$ & $591(3.0)$ \\
\hline Index diagnosis + 2yr & $247(1.2)$ & $333(1.7)$ & $591(3.0)$ \\
\hline $1994-1996$ & $253(1.3)$ & $338(1.7)$ & $591(3.0)$ \\
\hline
\end{tabular}

\begin{tabular}{|c|c|c|c|}
\hline CHF & 3 Codes (GE) & 2 Codes (GE) & 1 Codes (GE) \\
\hline Index Diagnosis + 1 yr & $344(1.7)$ & $467(2.4)$ & $823(4.2)$ \\
\hline Index Diagnosis $+2 \mathrm{yr}$ & $373(1.9)$ & $488(2.5)$ & $823(4.2)$ \\
\hline $1994-1996$ & $380(1.9)$ & $494(2.5)$ & $823(4.2)$ \\
\hline
\end{tabular}

\begin{tabular}{|c|c|c|c|}
\hline LHF & 3 Codes (GE) & 2 Codes (GE) & 1 Codes (GE) \\
\hline index Diagnosis $+1 \mathrm{yr}$ & $24(0.1)$ & $41(0.2)$ & $101(0.5)$ \\
\hline Index Diagnosis $+2 \mathrm{yr}$ & $26(0.1)$ & $42(0.2)$ & $101(0.5)$ \\
\hline $1994-1996$ & $26(0.1)$ & $42(0.2)$ & $101(0.5)$ \\
\hline
\end{tabular}

\begin{tabular}{|c|c|c|c|}
\hline HHF & 3 Codes (GE) & 2 Codes (GE) & 1 Codes (GE) \\
\hline index Diagnosis +1 yr & $40(0.2)$ & $68(0.3)$ & $155(0.8)$ \\
\hline Index Diagnosis +2 yr & $44(0.2)$ & $71(0.4)$ & $155(0.8)$ \\
\hline $1994-1996$ & $44(0.2)$ & $71(0.4)$ & $155(0.8)$ \\
\hline
\end{tabular}

\begin{tabular}{|l|l|}
\hline $\mathrm{CAD}$ & $=$ Coronary Artery Disease \\
\hline $\mathrm{MI}$ & $=$ Post Myocardial Infarction \\
\hline $\mathrm{CHF}$ & $=$ Congestive Heart Failure \\
\hline $\mathrm{LHF}$ & $=$ Left Heart Failure \\
\hline $\mathrm{HHF}$ & $=$ Hypertensive Heart Failure \\
\hline
\end{tabular}


Table. Operational Definitions of Prevalent Cases of Hypertension and Relevant Comorbities, according to number of codes required and time interval for observing the codes, with frequencies and (proportions) reported. $\mathrm{N}=19,707$ from a $50 \%$ random sample

\begin{tabular}{|c|c|c|c|}
\hline COPD & 3 Codes (GE) & 2 Codes (GE) & 1 Codes (GE) \\
\hline Index Diagnosis + 1yr & $1.123(5.7)$ & $1.929(9.8)$ & $3,884(19.7)$ \\
\hline Index Diagnosis + 2yr & $1.401(7.1)$ & $2,159(11.0)$ & $3,884(19.7)$ \\
\hline $1994-1996$ & $1.477(7.5)$ & $2,216(11.2)$ & $3,884(19.7)$ \\
\hline
\end{tabular}

\begin{tabular}{|c|c|c|c|}
\hline ASTH & 3 Codes (GE) & 2 Codes (GE) & 1 Codes (GE) \\
\hline Index Diagnosis + 1yr & $737(3.7)$ & $1,155(5.9)$ & $2,083(10.6)$ \\
\hline Index Diagnosis + 2yr & $894(4.5)$ & $\frac{1,266(6.4)}{2,083}$ & $\frac{208}{10.6)}$ \\
\hline $1994-1996$ & $934(4.7)$ & $1,291(6.6)$ & $2,083(10.6)$ \\
\hline
\end{tabular}

\begin{tabular}{|c|c|c|c|}
\hline DM & 3 Codes (GE) & 2 Codes (GE) & 1 Codes (GE) \\
\hline Index Diagnosis +1 yr & $2,668(13.5)$ & $3,173(16.1)$ & $4,341(22.0)$ \\
\hline Index Diagnosis +2 yr & $2,906(14.7)$ & $3,311(16.8)$ & $4,341(22.0)$ \\
\hline $1994-1996$ & $2,945(14.9)$ & $3,341(17.0)$ & $4,341(22.0)$ \\
\hline
\end{tabular}

\begin{tabular}{|c|c|c|c|}
\hline DMT1 & 3 Codes (GE) & 2 Codes (GE) & 1 Codes (GE) \\
\hline Index Diagnosis + 1 yr & $224(1.1)$ & $314(1.6)$ & $583(3.0)$ \\
\hline Index Diagnosis + 2yr & $252(1.3)$ & $343(1.7)$ & $583(3.0)$ \\
\hline $1994-1996$ & $260(1.3)$ & $348(1.8)$ & $583(3.0)$ \\
\hline
\end{tabular}

\begin{tabular}{|l|l|}
\hline COPO & $=$ Chronic Obstructive Pulmonary Disease \\
\hline ASTH & $=$ Asthma \\
\hline DM & $=$ Diabetes Mellitus \\
\hline DMT1 & $=$ Diabetes Mellitus Type 1 \\
\hline
\end{tabular}


Table. Operational Definitions of Prevalent Cases of Hypertension and Relevant Comorbities, according to number of codes required and time interval for observing the codes, with frequencies and (proportions) reported $\mathrm{N}=19,707$ from a $50 \%$ random sample

\begin{tabular}{|c|c|c|c|}
\hline KID & 3 Codes (GE) & 2 Codes (GE) & 1 Codes (GE) \\
\hline Index Diagnosis $+1 \mathrm{yr}$ & $414(2.1)$ & $548(2.8)$ & $920(4.7)$ \\
\hline Index Diagnosis $+2 \mathrm{yr}$ & $444(2.3)$ & $585(3.0)$ & $920(4.7)$ \\
\hline $1994-1996$ & $455(2.3)$ & $588(3.0)$ & $920(4.7)$ \\
\hline
\end{tabular}

\begin{tabular}{|c|c|c|c|}
\hline DMNeph 1 & 3 Codes (GE) & 2 Codes (GE) & 1 Codes (GE) \\
\hline Index Diagnosis $+1 \mathrm{yr}$ & $64(0.3)$ & $100(0.5)$ & $173(0.9)$ \\
\hline Index Diagnosis $+2 \mathrm{yr}$ & $82(0.4)$ & $113(0.6)$ & $173(0.9)$ \\
\hline $1994-1996$ & $86(0.4)$ & $114(0.6)$ & $173(0.9)$ \\
\hline
\end{tabular}

\begin{tabular}{|c|c|c|c|}
\hline DMNeph2 & 3 Codes (GE) & 2 Codes (GE) & 1 Codes (GE) \\
\hline Index Diagnosis +1 yr & $163(0.8)$ & $195(1.0)$ & $252(1.3)$ \\
\hline Index Diagnosis +2 yr & $175(0.9)$ & $203(1.0)$ & $252(1.3)$ \\
\hline $1994-1996$ & $179(0.9)$ & $205(1.0)$ & $252(1.3)$ \\
\hline
\end{tabular}

\begin{tabular}{|c|c|c|c|}
\hline HRF & 3 Codes (GE) & 2 Codes (GE) & 1 Codes (GE) \\
\hline Index Diagnosis + 1yr & $114(0.6)$ & $186(0.9)$ & $410(2.1)$ \\
\hline Index Diagnosis $+2 \mathrm{yr}$ & $127(0.6)$ & $205(1.0)$ & $410(2.1)$ \\
\hline 1994-1996 & $137(0.7)$ & $207(1.0)$ & $410(2.1)$ \\
\hline
\end{tabular}

\begin{tabular}{|c|c|c|c|}
\hline ORF & 3 Codes (GE) & 2 Codes (GE) & 1 Codes (GE) \\
\hline Index Diagnosis +1 yr & $339(1.7)$ & $421(2.1)$ & $654(3.3)$ \\
\hline Index Diagnosis +2 yr & $361(1.8)$ & $444(2.3)$ & $654(3.3)$ \\
\hline $1994-1996$ & $367(1.9)$ & $446(2.3)$ & $654(3.3)$ \\
\hline
\end{tabular}

\begin{tabular}{|l|l|}
\hline KID & $=$ Renal Failure \\
\hline DMNeph1 & $=$ Diabetic Nephropathy (Definition 1) \\
\hline DMNeph2 & $=$ Diabetic Nephropathy (Definition 2) \\
\hline HRF & $=$ Hypertensive Renal Failure \\
\hline ORF & = Other Renal Failure \\
\hline
\end{tabular}




\begin{tabular}{|c|c|}
\hline COPD & $=$ Chronic Obstructive Pulmonary Disease \\
\hline ASTH & $=$ Asthma \\
\hline $\mathrm{BPH}$ & $=$ Benign Prostatic Hyperplasia \\
\hline LIP & $=$ Dyslipidemia \\
\hline CAD & $=$ Coronary Artery Disease \\
\hline $\mathrm{MI}$ & $=$ Post Myocardial infarction \\
\hline$\overline{\mathrm{CHF}}$ & = Congestive Heart Failure \\
\hline $\mathrm{LHF}$ & $=$ Left Heart Failure \\
\hline HHF & $=$ Hypertensive Heart Failure \\
\hline DM & $=$ Diabetes Mellitus \\
\hline DMT1 & $=$ Diabetes Mellitus Type 1 \\
\hline $\mathrm{KIO}$ & $=$ Renal Failure \\
\hline DMNeph1 & = Diabetic Nephropathy (Definition 1) \\
\hline DMNeph2 & $=$ Diabetic Nephropathy (Definition 2) \\
\hline $\mathrm{HRF}$ & $=$ Hypertensive Renal Failure \\
\hline$\overline{\mathrm{ORF}}$ & $=$ Other Renal Failure \\
\hline DI & $=$ Diuretics \\
\hline $\mathrm{BB}$ & $=$ Beta Blockers \\
\hline$\overline{\mathrm{CCB}}$ & = Calcium Channel Blockers \\
\hline ACEI & = Angiotensin Converting Enzyme Inhibitors \\
\hline $\mathrm{AB}$ & = Alpha Blockers \\
\hline ARB & $=$ Angiotensin Receptor Blockers \\
\hline SY & = Sympatholytics \\
\hline VD & $=$ Vasodilators \\
\hline
\end{tabular}




\section{BIBLIOGRAPHY}

Burt VL, Whelton P, Roccella EJ et al. Prevalence of hypertension in the US adult population: results from the Third National Health and Nutrition Examination Survey, 1988-1991. Hypertension 1995; 25: 305-313.

Donabedian A. Evaluating the quality of medical care. Millbank Memorial Fund Quarterly 1966; 166-206.

Drake DF. Managed care: a product of market dynamics. Journal of the American Medical Association 1997; 277: 560-563.

Glauber HS and Brown JB. Use of health maintenance organization data bases to study pharmacy resource usage in diabetes mellitus. Diabetes Care $1992 ; 15 ; 870-876$.

Hawaii Medical Services Association Foundation. Overview of resources for research at HMSA. (1995)

Health Care Financing Administration. International Classification of

Diseases, $9^{\text {th }}$ Revision. US Department of Heaith and Human Servives, Public Health Service, Health Care Financing Administration (1994)

Hennekens $\mathrm{CH}$, Albert CM, Godfried SL, Gaziano JM, and Buring JE. Adjunctive drug therapy of acute myocardial infarction-evidence from clinical trials. New England Joumal of Medicine 1996; 335: 1660-1667.

lezzoni LI. Assessing quality using administrative data. Annals of Internal Medicine 1997; 127: 666-674.

Jencks SF and Wilensky GR. The health care quality initiative. Journal of the American Medical Association 1992; 168: 900-903.

Joint Commission on Accreditation of Healthcare Organizations. Improving organizational performance. In: Accreditation manual for home care. (1994) JCAHO, Oakbrook Terrace Illinois, p. 162.

Joint National Committee on Prevention, Detection, Evaluation, and Treatment of High Blood Pressure and the National High Blood Pressure Education Program Coordinating Committee. The sixth report of the joint national committee on prevention, detection, evaluation, and treatment of high blood pressure. Archives of Intermal Medicine 1997; 157: 2413-2446. 
Joint National Committee on Detection, Evaluation, and Treatment of High Blood Pressure. The fifth report of the Joint National Committee on Detection. Evaluation, and Treatment of High Blood Pressure (JNC V). Archives of Internal Medicine 1993; 153: 154-183.

Kannel WB. Blood pressure as a cardiovascular risk factor: prevention and treatment. Joumal of the American Medical Association 1996; 275: 1571-1576.

Kaplan NM. Treatment of hypertension: drug therapy. In: Clinical Hypertension, $7^{\text {th }}$ ed. 181-263. (1998a)

Kaplan NM. Treatment of hypertension: drug therapy. In: Clinical Hypertension, $6^{\text {th }}$ ed. 191-280. (1994)

Kaplan NM. Management of Hypertension, 5th Ed. Durant OK: Essential Information Systems, 1993.

Kaplan NM. Gifford RW. Choice of initial therapy for hypertension. Journal of the American Medical Association 1996; 275: 1577-1580.

Kapian NM. Treatment of hypertension: rationale, guidelines, and goals. In: Clinical Hypertension, $7^{\text {th }}$ ed. $133-158$ (1998b) p. 133.

Kaplan NM. Hypertension in the population at large. In: Clinical Hypertension $7^{\text {th }}$ ed. 1-17. (1998c)

Kaplan NM. Primary hypertension: natural history, special populations, and evaluation. In: Clinical Hypertension, $7^{\text {th }}$ ed. 101-132. (1998d)

Kaplan NM. Treatment of hypertension: nondrug therapy. In: Clinical Hypertension, $7^{\text {th }}$ ed. $159-179(1998 \mathrm{e})$

Levy DL, Larson, MG, Ramachandran SV, Kannel, WB, Ho KKL. The progression from hypertension to congestive heart failure. Journal of the American Medical Association 1996; 275: 1557-1562.

Margolis S, Klag MJ. Hypertension. 1998. The Johns Hopkins White Papers. The Johns Hopkins Medical Institutions, Baltimore, Md.

Melum MM. Total quality outcomes management: a guide to integrating outcomes measurement and TQM to improve health care. (1995) GOAL/QPC, Methuen, MA 
Mehta SS, Wilcox CS, and Schulman KA. Treatment of hypertension in patients with comorbidities: results from the study of hypertensive prescribing practices (SHyPP). American Joumal of Hypertension 1999; 12: 333-40.

Midgley JP, Matthew AG, Greenwood CM, Logan AG. Effect of reduced dietary sodium on blood pressure: A meta-analysis of randomized controlled trials. Journal of the American Medical Association 1996; 275: 1590-1597.

Moser $M$. Why are physicians not prescribing diuretics more frequently in the management of hypertension? Joumal of the Amenican Medical Association $1998 ; 1813-1816$.

O'Connor PJ, Rush WA, Pronk NP, and Cherney LM. Identifying diabetes mellitus or heart disease among health maintenance organization members: sensitivity, specificity, predictive value, and cost of survey and database methods. Amenican Joumal of Managed Care 1998; 4: 335-342.

Palmer RH. Process-based measures of quality: the need for detailed clinical data in large health care databases. Annals of internal Medicine 1997; 127: 733-738.

President's Advisory Commission on Consumer Protection and Quality in the Health Care Industry. Quality first: better health care for all Americans. 1998. US Government Printing Office, Washington, DC

Quam L, Ellis LBM, Venus MA, Clouse J, Taylor CG, and Leatherman S. Using claims data for epidemiologic research: the concordance of claimsbased criteria with the medical record and patient survey for identifying a hypertensive population. Medical Care 1993; 31: 498-507

SAS Institute. SAS Procedures Guide, Version 6, $3^{\text {rd }}$ ed. (1995a)

SAS Institute. Logistic regression examples: using the SAS system. Version $6,1^{\text {st }}$ ed. $(1995 \mathrm{~b})$

Siegel $\mathrm{D}$ and Lopez J. Trends in antihypertensive drug use in the United States: Do the JNC $V$ recommendations affect prescribing? Journal of the American Medical Association 1997; 278: 1745-1779.

Toscani MR. Moving toward a health management system. In: Pharmacoeconomics and outcomes 1997; American College of Clinical Pharmacy. p.15-37. 
The Treatment of Mild Hypertension Study Research Group. The treatment of mild hypertension: a randomized, placebo-controlled trial of a nutritionalhygienic regimen along with various drug monotherapies. Archives of intemal Medicine 1991; 151: 1413-1423.

Woodwell DA. National Ambulatony Medical Care Survey. 1995 Summary Advance data from vital and health statistics; no. 286. Hyattsville, Maryland. National Center for Health Statistics, 1997. 